OPEN ACCESS

Edited by:

Cesar de la Fuente-Nunez, University of Pennsylvania,

United States

Reviewed by:

Marc Maresca,

Aix-Marseille Université, France

Jicong Cao,

Massachusetts Institute of Technology, United States

*Correspondence:

Ruoyu Mao

maoruoyu@caas.cn;

rain_mry@126.com

Jianhua Wang

wangjianhua@caas.cn;

2681298635@qq.com

tThese authors have contributed equally to this work and share first authorship

Specialty section: This article was submitted to

Microbiotechnology,

a section of the journal

Frontiers in Microbiology

Received: 04 December 2020 Accepted: 26 February 2021

Published: 18 March 2021

Citation:

Shen $W$, Yang $N$, Teng $D$, Hao $Y$, Ma X, Mao R and Wang J (2021)

Design and High Expression of Non-glycosylated Lysostaphins in Pichia pastoris and Their

Pharmacodynamic Study.

Front. Microbiol. 12:637662. doi: 10.3389/fmicb.2021.637662

\section{Design and High Expression of Non-glycosylated Lysostaphins in Pichia pastoris and Their Pharmacodynamic Study}

\author{
Wenluan Shen ${ }^{1,2+}$, Na Yang ${ }^{1,2+}$, Da Teng ${ }^{1,2}$, Ya Hao ${ }^{1,2}$, Xuanxuan Ma ${ }^{1,2}$, Ruoyu Mao ${ }^{1,2 *}$ and \\ Jianhua Wang ${ }^{1,2 *}$ \\ ${ }^{1}$ Gene Engineering Laboratory, Feed Research Institute, Chinese Academy of Agricultural Sciences, Beijing, China, ${ }^{2}$ Key \\ Laboratory of Feed Biotechnology, Ministry of Agriculture and Rural Affairs, Beijing, China
}

Lysostaphin is an effective antimicrobial agent to Staphylococcus, especially for the methicillin-resistant Staphylococcus aureus (MRSA) and multidrug-resistant Staphylococcus aureus (MDRSA). In this study, the seven lysostaphin derived mutants (rLys) were designed to overcome the barrier of glycosylation during expression in Pichia pastoris. Among them, 127A and 127A232Q had highest antimicrobial activity (MIC values $0.07-0.3 \mu \mathrm{M})$ to $S$. aureus than others and the commercial lysostaphins (1-15.8 times). There was no glycosylation during the expression in 5- $L$ fermenter level, with the high yield of $1315 \mathrm{mg} / \mathrm{L}(127 \mathrm{~A})$ and $1141 \mathrm{mg} / \mathrm{L}$ (127A232Q), respectively. Meanwhile, 127A and 127A232Q effectively killed $99.9 \%$ of $S$. aureus at low concentration ( $1 \times$ MIC) within $30 \mathrm{~min}$, without the regrowth of pathogen. They also showed low toxicity, high $\mathrm{pH}$ and temperature stability. The results of in vivo therapeutic effect of $127 \mathrm{~A}$ and $127 \mathrm{~A} 232 \mathrm{Q}$ against high virulent S. aureus CVCC546 showed that $127 \mathrm{~A}$ and $127 \mathrm{~A} 232 \mathrm{Q}$ increased the survival rate of infected mice up to $100 \%$ at the dose of $10 \mathrm{mg} / \mathrm{kg}$ than the untreated group, reduced the bacterial translocation by 5-7 log CFU (over 99\%) in organs compared to the untreated group and alleviated multipleorgan injuries (liver, kidney and spleen). These data indicated that the non-glycosylated lysostaphin $127 \mathrm{~A}$ and $127 \mathrm{~A} 232 \mathrm{Q}$ may be a promising therapeutic agent against MDR staphylococcal infections.

Keywords: lysostaphins, non-glycosylation, P. pastoris expression, sepsis mouse model, pharmacodynamics

\section{INTRODUCTION}

Due to the chronic overuse of antibiotics, many resistant Staphylococcus aureus (S. aureus) emerged in recent years, such as methicillin-resistant $S$. aureus (MRSA), vancomycin-resistant S. aureus (VRSA), and multiple-drug-resistant $S$. aureus (MDRSA), this $S$. aureus become a formidable pathogen which can cause terrible infections in humans and livestock. Meanwhile, between 2 and 53 million persons are estimated to carry MRSA worldwide (Gleeson et al., 2015). 
In the United States, the fees for the 6-month treatment regimen against MRSA infection amount to nearly $\$ 36,000$ in 2013 (Laxminarayan et al., 2013). It has been estimated there would be about 10 million deaths every year and $\$ 100$ trillion lost to the global economy by 2050 (Review on Antimicrobial Resistance, $\left.2017^{1}\right)$. Therefore, the new anti-S. aureus agents with potent activity and low resistance are urgent needed.

Lysostaphin is a zinc metalloprotease from Staphylococcus staphylolyticus (Schindler and Schuhardt, 1964), and it has the activity of glycylglycine endopeptidase to lyses other Staphylococcus species such as $S$. aureus. The minimum inhibitory concentrations (MICs) of lysostaphin to various strains of $S$. aureus were ranged from $0.001-8.0 \mu \mathrm{g} / \mathrm{mL}$ (Climo et al., 1998; von Eiff et al., 2003; Yang et al., 2007). As early as in 1974, a $500 \mathrm{mg}$ single dose of lysostaphin could showed eutherapeutic efficacy in a myelocytic leukemia patient suffering from multidrug-resistant staphylococcal pneumonia, multiple metastatic staphylococcal abscesses, and cellulitis (Zygmunt and Tavormina, 1972; Stark et al., 1974). Lysostaphin is very effective in protecting mouse models of systemic $S$. aureus infection from both methicillin-sensitive $S$. aureus (MSSA) and MRSA (Kokai-Kun et al., 2003). In the murine model of catheterassociated $S$. aureus biofilms, systemic lysostaphin administration was shown to clear established biofilms during a 4-day treatment, and a single prophylactic dose prevented subsequent biofilm formation on indwelling cath (Kokai-Kun et al., 2009).

The gene of lysostaphin was cloned in 1987 (Recsei et al., 1987; Kokai-Kun, 2012). The preproenzyme of lysostaphin is composed of 493 amino acids. The first 36 amino acids at the $\mathrm{N}$-terminal are signal peptides region. When protein trafficking, they are located in the endoplasmic reticulum and then removed. This full protein sequence with 457 amino acids consisted of a propeptide of 211 amino acids from which 195 amino acids are assembled in 15 tandem repeats of 13 amino acids length, and a hydrophobic mature lysostaphin 246 amino acids (27 KDa) (Bastos et al., 2010). The crystal structure of mature lysostaphin has been resolved (Sabala et al., 2014), and it mainly includes three parts: 132 amino acids of catalytic domain (CAT), 102 amino acids of cell-wall-targeting domain (CWT) and 13 amino acids of linker between them.

The mechanism of lysostaphin to bacteria is to destroy the cell wall of Staphylococcus (Johnson et al., 2018; Gonzalez-Delgado et al., 2020). Pentaglycine crossbridges of peptidoglycan (PG) is the component of Staphylococcus aureus cell wall and an explicit target of Lys (Vollmer et al., 2008). When Lys combined with PG, the CAT domain destroys the bond between the second and third Glycine, and the structure of the cell wall of $S$. aureus is damaged, achieving a sterilization effect (Tossavainen et al., 2018; Grishin et al., 2019).

The clinical application of lysostaphin depends on the availability of large amounts of highly purified protein from a safe and nonpathogenic source. Firstly, lysostaphin was extracted from the culture of its natural host S. simulans (Chandra et al., 2018). Due to the technical difficulty, and the safety dispute, it cannot be used in actual production (Kokai-Kun, 2012). At

${ }^{1}$ http://amr-review.org present, most of the lysostaphin is obtained from the recombined expression, among which prokaryotic expression systems include E. coli (Sharma et al., 2006; Duman et al., 2019), and Lactococcus lactis (Mierau et al., 2005), with the yield of 50-300 mg/L, meanwhile, they had the disadvantages of higher cost and complex purification process. The eukaryotic expression systems include Pichia pastoris (Zhao et al., 2014), animal mammary epithelial cells (Fan et al., 2002), and etc. With the yield of 200$1000 \mathrm{mg} / \mathrm{L}$. In the eukaryotic expression system, the expression of lysostaphin has encountered the barrier of glycosylation (Chen and Harcum, 2006). It has been shown that the activity of these glycosylated lysostaphins is lower than that of the non-glycosylated enzymes, and the other band is not easy to separate during purification. The glycosylation sites mutant could disrupt the N-terminal glycosylation of lysostaphin in P. pastoris. However, the yield of the derived lysostaphin was $500 \mathrm{mg} / \mathrm{L}$ (Zhao et al., 2014), which still have gaps to the demand of large-scale industrial production. In this study, the glycosylation site of lysostaphin was modified to obtain the non-glycosylated lysostaphin mutants. The 127A and 127A232Q had highest activity and yields. And the in vivo and in vitro activities were characterized. Additionally, the efficacy of 127A and 127A232Q were determined in a peritonitis mouse model of lethal infection with MDR S. aureus.

\section{MATERIALS AND METHODS}

\section{Strains, Plasmids and Reagents}

The Escherichia coli $\mathrm{DH} 5 \alpha, P$. pastoris X-33, and $\mathrm{pPICZ} \alpha \mathrm{A}$ vectors used in cloning and expression were purchased from Invitrogen. The restriction enzymes were purchased from Tiangan Biotech (China, Beijing). The test strains, including S. aureus ATCC 43300, S. aureus ATCC 25923 were purchased from the American Type Culture Collection (ATCC) (Beijing, China), S. aureus CICC 10436, S. aureus CICC 10473, S. aureus CICC 21601, S. epidermidis CICC 23962, S. epidermidis CICC 10294 were purchased from China Center of Industrial Culture Collection (CICC) (Beijing, China), S. aureus CVCC 546 were purchased from China Veterinary Culture Collection Center(CVCC) (Beijing, China), S. epidermidis CGMCC 1.4206 was purchased from China General Microbiological Culture Collection Center (CGMCC) (Beijing, China), S. hyicus NCTC 10350 was purchased from National Collection of Type Cultures (NCTC). The bovine clinical MDR S. aureus E48 strain was donated by Prof. Zhao Xin (Northwest A\&F University) and numbered as FRI-GEL160701.The S. aureus ky, S. hyicus 437-2, S. sciuri 26, S. sciuri 31 were obtained from clinical trials and numbered as FRI-GEL180901, ACCC61734 (Agricultural Culture Collection of China), FRI-GEL180902, FRI-GEL180903, respectively.

The enzymes used in DNA restriction and DNA linkage were purchased from New England Biolabs (NEB, Beijing, China). The plasmid and DNA extraction kits were purchased from TIANGEN Biotech (Beijing, China). The commercial Lysostaphin was purchased from Sigma-Aldrich (Shanghai, China). Other reagents were analytical grade. 


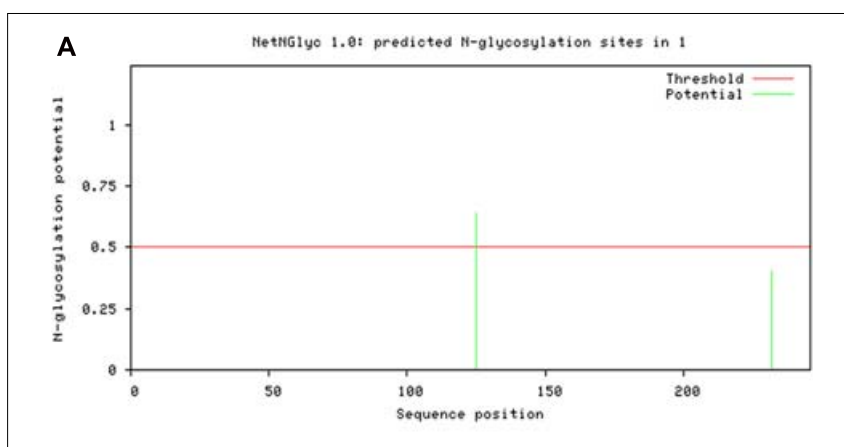

B

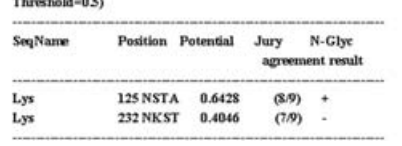

FIGURE 1 | Analysis of glycosylation site of Lys sequence. (A) Probability of glycosylation at two potential sites (B) Result of Glycosylation site prediction.

\section{Design of Non-glycosylated Lysostaphin Genes}

$\mathrm{N}$-linked glycosylation sequons were identified by NetNGlyc 1.0 Server $^{2}$ (Figure 1). In order to disrupt the aberrant glycosylation of the wild-type protein sequence, seven optimized recombinant Lysostaphin (rLys) sequences were designed including 125Q (Asn to Gln at position 125), 232Q (Asn to Gln at position 232), 125Q232Q (Asn to Gln at positions of both 125 and 232), 126P (Ser to Pro at position 126), 126P 232Q (Ser to Pro at position 126 and Asn to Gln at position 232), 127A (Thr to Ala at position 127), 127A232Q (Thr to Ala at position 127 and Asn to Gln at position 232) and a wild-type lysostaphin (Lys) sequence. Codon optimized gene sequences of rLys and Lys were designed using the Reverse Translate Tool $^{3}$ based on the preferential codon usage of $P$. pastoris ${ }^{4}$ (Supplementary Figure 1).

\section{Construction of Recombinant Plasmid pPICZ $\alpha$ A-rLys/Lys and Transformation to P. pastoris $\mathrm{X}-33$}

Every DNA sequence composed of an XhoI restriction site, a $P$. pastoris Kex2 protease cleavage site, the rLys or Lys gene, two stop codons, and an $\mathrm{XbaI}$ restriction site. These specific genes were cloned into the plasmid of PUC19 in Escherichia coli DH5a. The rLys/Lys primers (rLys-F, 5'-CCGCTCGAGAAGAGAGCTGCTACTCATGAA-3'; rLys-R, $5^{\prime}$-GATTATTACTTAATAGTATCTCGACCCCAC-3') and the genes were synthesized by Sangon Biotech (Shanghai, China). The plasmids containing the target genes were extracted and used as a PCR template for the amplification of the rLys gene. The amplified DNA fragments and plasmid pPICZ $\alpha$ A were digested with XhoI and XbaI simultaneously. Connected the digested DNA and plasmid to construct a Pichia expression

\footnotetext{
${ }^{2}$ http://www.cbs.dtu.dk/services/NetNGlyc/

${ }^{3}$ http://bioinformatics.org//sms2/rev_trans.html

${ }^{4}$ http://www.kazusa.or.jp/codon/
}

vector $\mathrm{pPICZ} \alpha \mathrm{A}$-rLys/Lys and transformed into E. coli $\mathrm{DH} 5 \alpha$. Positive sequences were identified and confirmed by PCR and DNA sequencing (Zhang et al., 2011).

The linearized pPICZ $\alpha$ A-rLys vectors were transformed into $P$. pastoris $\mathrm{X}-33$ by electroporation. The positive transformants were selected on YPDS plates with $100 \mu \mathrm{g} / \mathrm{mL}$ of Zeocin (Zhang et al., 2015).

\section{Expression of rLys/Lys in the 48-Well Plates, Shaking Flask, and Fermenter Level}

In each mutant, 45 positive recombinants were selected and inoculated on 48-well plates in BMGY medium and cultured at $29^{\circ} \mathrm{C}, 250 \mathrm{rpm}$ for $24 \mathrm{~h}$, then methanol (100\%) was added every $24 \mathrm{~h}$ to a final concentration at $0.5 \%(\mathrm{v} / \mathrm{v})$. The supernatant was collected. Inhibition zone assay was used to select the recombinants with the highest activity. Expression at $1 \mathrm{~L}$ shake flasks: The positive transformants were inoculated in $10 \mathrm{ml}$ of YPD medium, containing $100 \mu \mathrm{g} / \mathrm{mL}$ of Zeocin and shaken until an optical density (OD)600 nm of $4.0-6.0$ at $29^{\circ} \mathrm{C}$ and $250 \mathrm{rpm}$ was obtained. The cells were harvested by centrifugation at $4000 \mathrm{rpm}$ and $4^{\circ} \mathrm{C}$ for $5 \mathrm{~min}$ and resuspended to an OD600 $\mathrm{nm}$ of 1.0 in BMGY medium to induce the expression of the Lys/rLys at $29^{\circ} \mathrm{C}$ and $250 \mathrm{rpm}$. Methanol (100\%) was added to a final concentration of $0.5 \%$. The samples were centrifuged at $10,000 \times g$ for a 120 -h induction period, and every $24 \mathrm{~h}$ during that period, cells were removed from the centrifuge for $10 \mathrm{~min}$ and supernatant was subjected to Tricine-sodium dodecyl sulfate (SDS)-PAGE (Zhang et al., 2015).

Expression at $5 \mathrm{~L}$ bioreactors: A single colony from a positive transformant was incubated in $10 \mathrm{~mL}$ of YPD medium containing $100 \mu \mathrm{g} / \mathrm{mL}$ of Zeocin overnight at $29^{\circ} \mathrm{C}$. A $2 \mathrm{ml}$ cell suspension was inoculated into $200 \mathrm{~mL}$ YPD medium and shaken at $29^{\circ} \mathrm{C}$ for $16 \mathrm{~h}$. Once the seed culture reached an OD600 $\mathrm{nm}$ of 6.0 (late logarithmic growth phase), it was transferred into a 5liter fermentor (BIOSTATB plus, Sartorius Stedim Biotech) and incubated as previously described. During the induction, the dissolved oxygen, temperature and $\mathrm{pH}$ were maintained at $40 \%$, $29^{\circ} \mathrm{C}$ and 5.5, respectively. The total secreted protein levels in the fermentation broth were determined by the Bradford protein assay (Tiangen, Beijing, China) (Zhang et al., 2015).

\section{Purification of rLys/Lys}

The fermentation supernatant was collected by centrifugation (5000 rmp, $30 \mathrm{~min}$ ), filtered with micro-filtration membranes $(0.45 \mu \mathrm{m})$, and dialyzed with $10 \mathrm{KDa}$ cutoff dialysis tubing. The product was applied to a SP F.F. column. The protein samples were eluted by increasing the $\mathrm{NaCl}$ concentration in a stepwise manner. Firstly, the $100 \mathrm{mM} \mathrm{NaCl}, \mathrm{pH} 7.5$ was used to elute, then the concentration of $\mathrm{NaCl}$ was increased to $290 \mathrm{mM}$, and the eluent of corresponding elution peak was collected, dialyzed and freeze-dried (Zhang et al., 2015).

\section{Deglycosylation Experimental}

The purified protein 127A, 127A232Q and Lys (100 $\mu \mathrm{g}$ ) was dissolved into $40 \mu \mathrm{L} \mathrm{H}_{2} \mathrm{O}$. A $5 \mu \mathrm{L}$ of Deglycosylation Mix Buffer 
2 was added into the protein liquid, and incubated at $75^{\circ} \mathrm{C}$ for $10 \mathrm{~min}$, and then added $5 \mu \mathrm{L}$ Protein Deglycosylation Mix II after cooling down, and mixed gently. The mixture was incubated at $25^{\circ} \mathrm{C}$ for $30 \mathrm{~min}$, and then at $37^{\circ} \mathrm{C}$ for $1 \mathrm{~h}$. Finally, SDS-PAGE was used to verify deglycosylation.

\section{Minimal Inhibitory Concentration (MIC) Assay}

The MIC values of purified rLys/Lys were determined by the microtiter broth dilution method. Ten Staphylococcus standard strains and 5 clinical strains were used in this study. A clone of the strains was grown in $10 \mathrm{~mL}$ of Mueller-Hinton Broth (MHB) medium at $37^{\circ} \mathrm{C}, 250 \mathrm{rpm}$ overnight. The overnight culture was transferred into a MHB medium to the final concentration at $1 \%(\mathrm{v} / \mathrm{v})$, shaken at $37^{\circ} \mathrm{C}, 250 \mathrm{rpm}$, until OD600 $\mathrm{nm}$ reached 0.5 , and diluted to $1 \times 10^{5} \mathrm{CFU} / \mathrm{mL}$ with fresh MHB medium. Then purified rLys/Lys were two-fold serial dilutions from 1280 to $0.625 \mu \mathrm{g} / \mathrm{mL}$ with gradient concentration. A $90 \mu \mathrm{L}$ of the bacteria suspension and $10 \mu \mathrm{L}$ of serial concentration rLys/Lys were added in every well of 96 -well plates. The 96 -well plates were incubated at $37^{\circ} \mathrm{C}$ for $18-24 \mathrm{~h}$. The MIC was defined as the lowest concentration of ones at which there was $99.9 \%$ bacteria were killed. All assays were performed in triplicate (Cao et al., 2015).

\section{TIME-KILL ASSAY}

Staphylococcus aureus ATCC 43300 strains were grown in MHB medium overnight at $37^{\circ} \mathrm{C}, 250 \mathrm{rpm}$. Fresh $\mathrm{MHB}$ medium was inoculated with $1 \%(\mathrm{v} / \mathrm{v})$ of overnight culture and grown to mid-log phase $\left(\mathrm{OD}_{600} \mathrm{~nm}=0.5\right)$. The bacterial culture was diluted to $1 \times 10^{5} \mathrm{CFU} / \mathrm{mL}$ with fresh $\mathrm{MHB}$ medium. The purified rLys/Lys was added in the bacterial culture diluted and the final concentrations were to $1 \times, 2 \times$, or $4 \times \mathrm{MIC}$, respectively. The $100 \mu \mathrm{L}$ of mixture was added in 12 wells of 24 -well plates and cultured at $37^{\circ} \mathrm{C}, 250 \mathrm{rpm}$. The sample was taken out from each well at $0,0.5,1,1.5,2.5,3.5,5,6.5,8$, 10,12 , and $24 \mathrm{~h}$ to determine the in vitro pharmacodynamics. Ampicillin was also tested with the same concentration gradient as control, and the fresh MHB was the negative control. All experiments were performed in triplicate, and the statistical analyses of the experimental data were done with Graphpad 7.0 (Yang et al., 2019).

\section{Synergism Assays of 127A, 127A232Q, Lys With Traditional Antibiotics}

The chequerboard method was used for the measurement of interaction between the rLys/Lys and four kinds of antimicrobial agents with different mechanism including ampicillin, kanamycin, nisin, and ciprofloxacin. S. aureus ATCC 43300 was used in this assay. The rLys/Lys and antibiotics in a twofold dilution series were added into each well of the 96-well cell culture plates in a checkerboard fashion. The final concentrations of both rLys/Lys and antibiotics ranged from $1 / 16$ to $8 \times$ MIC to give a total volume in each well of 90 $\mu \mathrm{L}$. Other conditions were the same as in MIC assay. The fractional inhibitory concentration index (FICI) was used to evaluate the effect of synergism of each combination. FIC of rLys/Lys = MIC of rLys/Lys in combination with antibiotic/MIC of rLys/Lys alone; FIC of antibiotics = MIC of antibiotic in combination with (rLys/Lys)/MIC of antibiotic alone; FICI = FIC of rLys/Lys+antibiotic. The result of interaction between two antimicrobial drugs was determined based on FICI: FICI $\leq 0.5$ refers to synergy, $0.5<$ FICI $\leq 1$ refers to additivity, $1<$ FICI $\leq 4$ refers to indifference and FICI $>4$ refers to antagonism. All experiments were performed in triplicate (Zheng et al., 2017).

\section{Cytotoxicity Assay and Selectivity Index}

The RAW264.7 macrophage cells were used in the colorimetric MTT assay to test the cytotoxicity of rLys/Lys. Cells were resuspended to the final concentration at $2.5 \times 10^{5} \mathrm{cell} / \mathrm{mL}$ and a $100 \mu \mathrm{L}$ cell suspension was added into 96 -well plates at $37^{\circ} \mathrm{C}$ for $24 \mathrm{~h}$. A series of rLys/Lys solutions $(100 \mu \mathrm{L})$ were added and incubated for another $24 \mathrm{~h}, 5 \mathrm{mg} / \mathrm{L}$ MTT solution $(20 \mu \mathrm{L})$ was added into plates, incubated for $4 \mathrm{~h}$ in darkness. $150 \mu \mathrm{L}$ Dimethyl sulfoxide (DMSO) was added into plates and the absorbance was measured at $570 \mathrm{~nm}$ with a spectrophotometer. Untreated cells were used as controls. The rate of inhibition of cell proliferation was calculated using the following formula: Cell viability $(\%)=($ Abs570 $\mathrm{nm}$ of control-Abs570 $\mathrm{nm}$ of treated sample)/Abs570 $\mathrm{nm}$ of control $\times 100 \%$ (Yang et al., 2019). Selectivity index $(\mathrm{SI})=\mathrm{IC}_{50} / \mathrm{MIC}$. The $\mathrm{IC}_{50}$ is the cell half maximal inhibitory concentration, which was calculated by the Graphpad Prism 7.0 (Basso et al., 2010).

\section{Hemolysis}

Hemolytic activity of rLys/Lys to fresh mouse erythrocytes was assayed according to the standard method. In brief, a $100 \mu \mathrm{L}$ peptide solution with a final concentration of $0-512 \mu \mathrm{g} / \mathrm{mL}$ was mixed with a $100 \mu \mathrm{L}$ of $8 \%$ erythrocyte solution (diluted in $0.9 \% \mathrm{NaCl}$ ) and incubated for $1 \mathrm{~h}$ at $37^{\circ} \mathrm{C}$. Cells were centrifuged at $1500 \mathrm{rpm}$ for $5 \mathrm{~min}$, the supernatant was collected, and the absorbance was measured at $540 \mathrm{~nm}$. PBS and $0.1 \%$ Triton X-100 were used as the blank (A0) and positive (A100) control, respectively. Hemolysis of peptides was calculated by the following equation: Hemolysis $(\%)=[($ ALys - A0) $/(\mathrm{A} 100-$ A0) $] \times 100$.

\section{Effect of $\mathrm{pH}$ and Temperature on the Activity of 127A, 127A232Q}

The MIC value was used to determine the $\mathrm{pH}$ and temperature stability of rLys/Lys. Five values of $\mathrm{pH}$ gradient solutions $(100 \mathrm{mM})$ including glycine- $\mathrm{HCl}$ buffer $(\mathrm{pH} 2.0)$, sodium acetate buffer ( $\mathrm{pH} 4.0$ ), sodium phosphate buffer ( $\mathrm{pH}$ 6.0), Tris- $\mathrm{HCl}$ buffer ( $\mathrm{pH}$ 8.0), and glycine- $\mathrm{NaOH}$ buffer $(\mathrm{pH} 10.0)$ were used to incubate with rLys/Lys, at $37^{\circ} \mathrm{C}$ for $3 \mathrm{~h}$, respectively. The thermal stability of rLys/Lys was determined after a $1 \mathrm{~h}$ incubation at $4,25,40,50,60,80$, and $100^{\circ} \mathrm{C}$ in deionized water, separately. Deionized water served as independent controls. Subsequently, the antimicrobial activity of rLys/Lys against S. aureus ATCC 43300 was tested by MIC assays (Cao et al., 2015; Yang et al., 2017). 
TABLE 1 | The primers of Staphylococcus aureus virulence genes.

\begin{tabular}{|c|c|c|c|}
\hline Primer & Sequences $\left(5^{\prime}\right.$ to $\left.3^{\prime}\right)$ & $\begin{array}{c}\text { Number of } \\
\text { bases }\end{array}$ & $\begin{array}{c}\text { Gene } \\
\text { length (bp) }\end{array}$ \\
\hline \multirow[t]{2}{*}{$\operatorname{mec} A$} & GTAGAAATGACTGAACGTCCGATAA & 25 & 310 \\
\hline & CCAATTCCACATTGTTTCGGTCTAA & 25 & \\
\hline \multirow[t]{2}{*}{$p v l$} & ATCATTAGGTAAAATGTCTGGACATGATCCA & 31 & 433 \\
\hline & GCATCAAGTGTATTGGATAGCAAAAGC & 27 & \\
\hline \multirow[t]{2}{*}{ hla } & CTGATTACTATCCAAGAAATTCGATTG & 27 & 209 \\
\hline & CTITCCAGCCTACTIITTATCAGT & 25 & \\
\hline \multirow[t]{2}{*}{ clfA } & ATTGGCGTGGCTTCAGTGCT & 20 & 292 \\
\hline & CGTTCTTCCGTAGTTGCATTTG & 23 & \\
\hline \multirow[t]{2}{*}{ nuc } & ATGACAGAATACTTATTAAGTGCTGGC & 27 & 360 \\
\hline & TGTATCAACCAATAATAGTCTGAATGT & 27 & \\
\hline \multirow[t]{2}{*}{ sea } & GGTTATCAATGTGCGGGTGG & 20 & 102 \\
\hline & CGGCACTIITCTCTTCGG & 20 & \\
\hline \multirow[t]{2}{*}{ psm-mec } & GAAGATCTATCACAAGATGAAATA & 24 & 210 \\
\hline & ATGGATTTCACTGGTGTTATTACA & 24 & \\
\hline \multirow[t]{2}{*}{ cna } & AAAGCGTTGCCTAGTGGAGA & 20 & 192 \\
\hline & AGTGCCTTCCCAAACCTIT & 20 & \\
\hline \multirow[t]{2}{*}{ fnbpa } & GCGGAGATCAAAGACAA & 17 & 1279 \\
\hline & CCATCTATAGCTGTGTGG & 18 & \\
\hline \multirow[t]{2}{*}{ tsst-1 } & АССССTGTTСССТTATCATC & 21 & 326 \\
\hline & TाTTCAGTATTTGTAACGCC & 20 & \\
\hline
\end{tabular}

\section{Efficacy of rLys/Lys in vivo Identification of Virulence Genes in S. aureus CVCC 546}

The single clone of $S$. aureus CVCC 546 was cultured in $10 \mathrm{~mL}$ of $\mathrm{MHB}$ overnight at $37^{\circ} \mathrm{C}$. The genomic DNA was extracted using a TIANamp Bacteria DNA kit. The target genes were amplified with the virulence genes primers (Stürenburg, 2009; Qin et al., 2016; Waryah et al., 2016; Jahanshahi et al., 2018; Table 1). The product was analyzed by electrophoresis.

\section{The Sepsis Mouse Model}

Female BALB/c mice ( 6 weeks old, $25 \pm 2 \mathrm{~g}$ ) were purchased from the Beijing Vital River Laboratory Animal Technology Co., Ltd. All animal experiments were approved by the Laboratory Animal Ethical Committee in the Feed Research Institute of CAAS (AEC-CAAS-20090609). Operations were in accordance with ARRIVE guidelines.

\section{Absolute Lethal Dose of S. aureus ATCC 546 to Mice}

Mice were divided into four groups, each with five. Different concentrations $\left(5 \times 10^{8}, 10^{9}, 5 \times 10^{9}, 10^{10} \mathrm{CFU} / \mathrm{mL}\right)$ of S. aureus CVCC 546 were diluted with saline. Each mouse was intraperitoneally injected with $200 \mu \mathrm{L}$ diluted bacteria liquid. The absolute lethal dose was evaluated in $48 \mathrm{~h}$ after infection.

\section{Survival Rate of Mice}

The mice were divided into four groups ( 5 mice per group) and injected with $5,10 \mathrm{mg} / \mathrm{kg}$ of 127A, 127A232Q, Lys, C-Lys and 5, $10,20 \mathrm{mg} / \mathrm{kg}$ of ampicillin at $1 \mathrm{~h}$ post infection $\left(5 \times 10^{9} \mathrm{CFU} / \mathrm{mL}\right.$ of $S$. aureus CVCC 546, $200 \mu \mathrm{L}$ ). The survival rate was recorded daily for $72 \mathrm{~h}$ and the optimal therapeutic dose was identified.

\section{Bacteria Counts in the Tissue and Histological Section Experiment}

Mice (5 mice per group) were challenged with $S$. aureus CVCC $546\left(5 \times 10^{9} \mathrm{CFU} / \mathrm{mL}, 200 \mu \mathrm{L}\right)$ by intraperitoneal injection and treated with the $127 \mathrm{~A}, 127 \mathrm{~A} 232 \mathrm{Q}$, Lys, C-Lys $(10 \mathrm{mg} / \mathrm{kg})$ and ampicillin $(20 \mathrm{mg} / \mathrm{kg})$. Heart, liver, spleen and kidney were removed from mice at $24 \mathrm{~h}$ following the administration of S. aureus CVCC 546, and divided into two parts. One part of the tissues was homogenized in sterile PBS to the terminal concentration of $1 \mathrm{mg} / \mathrm{mL}$ to evaluate bacterial translocation by colony counting. All experiments were performed in triplicate. The other part of tissues was washed with PBS and fixed in paraformaldehyde. After they were washed with PBS, dehydrated with a graded series of ethanol (75-95\%) and infiltrated with xylene and embedded in paraffin wax. Sections were cut, stained with hematoxylin and eosin and examined under a light microscope. A scoring standard is established to assess the degree of sample damage (Beijing Blue Sea Biological Technology Co., Ltd.) (Table 2).

\section{Statistical Analysis}

All data were presented as the means \pm standard deviation (SD) and all statistical analyses were performed using GraphPad Prism software v8.0 (GraphPad Software, United States). Statistical significance of groups was analyzed using the one-way ANOVA and Tukey multiple comparison.

\section{RESULTS}

\section{Design of Synthetic Lysostaphin Genes}

Two consensus N-linked glycosylation sites located in the lysostaphin sequence, one is "N125-S126-T127" and the other is "N232-K233-T234" (Figure 1). It was confirmed that the residue N125 was thought to be located at the C-terminal end of the catalytic domain, which was essential for the activity of lysostaphin (Zhao et al., 2014). The amino acid residue Q, with similar structure and properties, was used as substitution in this position. Similarly, Q was also used in position 232. To minimize the structural changes caused by mutations, $\mathrm{P}$ with the structure constrain effect and A with the small and neutral side chain were used in position 126 and 127. As results, seven Lys derived sequences (rLys) were designed to avoid the glycosylation in $P$. pastoris expression system (Supplementary Figure 1).

\begin{tabular}{cccccccc}
\multicolumn{7}{l}{ TABLE 2 | Tissue section score. } \\
\hline & PBS & CK & 127A & 127A232Q & Lys & C-Lys & Amp \\
\hline Kidney & 0 & 3 & 0 & 1 & 1 & 1 & 1 \\
Spleen & 0 & 3 & 1 & 1 & 3 & 1 & 2
\end{tabular}

0, no inflammation; 1, very mild symptoms; 2 , mild symptoms; 3 , very serious. PBS, Uninfected group; $C K$, Untreated infection group. 


\section{Construction of Recombinant Plasmid pPICZ $\alpha$ A-rLys/Lys}

The rLys sequences were digested with the restrict enzyme XhoI and $X b a \mathrm{I}$, cloned into the $\mathrm{pPICZ} \alpha \mathrm{A}$ vector digested with the same enzyme (Figure 2A), and transformed into E. coli DH5 $\alpha$. Positive recombinants were corrected by PCR and sequencing (Figure 2B). The recombinant plasmid pPICZ $\alpha$ A-rLys/Lys was linearized with $P m e \mathrm{I}$ and transferred into $P$. patoris X-33 competent cells. The positive clones were survived on the YPDS plates with $100 \mu \mathrm{g} / \mathrm{mL}$ of Zeocin.

\section{Expression of rLys/Lys in the Shaking Flask Level}

The transformants of 126P-3, 126P-32, 126P232Q-6, 126P232Q38, 127A-3, 127A-15, 127A232Q-4, 127A232Q-8, 125Q-2, 125Q40, 232Q-3, 232Q-8, 125232Q-3, 125232Q-11, Lys-4, Lys-8 were selected in 48-well plates by inhibition zone assay (Figure 3A). After expression in $1 \mathrm{~L}$ shaking flask, 126P-3, 126P232Q-6, 127A-15, 127A232Q-8, 125Q-40, 232Q-3, 125232Q-3, Lys-4 was selected for the further research (Figure 3B). As shown in Figure 3C, the target band was observed at $24 \mathrm{~h}$ induction, and the yield increased with the induction time. There were two bands in the nature Lys gene product in Figure 3C, one was the Lys and the other was the glycosylation product. The variants except $232 \mathrm{Q}$ had single band, indicating the glycosylation was successfully avoided in $P$. pastoris. The molecular weight of selected rLys/Lys were evaluated by MALDITOP MS. The weight of 126P (26989.013 Da), 126P232Q $(26979.331 \mathrm{Da}), 127 \mathrm{~A}(26932.771 \mathrm{Da}), 127 \mathrm{~A} 232 \mathrm{Q}$ (26936.814 $\mathrm{Da})$, 125Q (26959.966 Da), $125232 \mathrm{Q}(27032.595 \mathrm{Da})$ were consistent with the theoretical weight $(27 \mathrm{KDa})$. However, there were two absorption peaks can be seen in the result of nature Lys. One peak is at $26956.751 \mathrm{Da}$, another is at 29438.351 $\mathrm{Da}$, which was consistent with the molecular weight of the product of N-linked glycosylation. Meanwhile, two peaks were also observed in the result of $232 \mathrm{Q}$. One of the peaks is at 26976.105 Da, another is at 29396.233 Da (Supplementary Figure 2), indicating that the site of 232 was not essential for the glycosylation in Lys.

\section{Antimicrobial Activity Assays to Bacteria}

The rLys, Lys and commercial Lys (C-Lys) had potent antimicrobial activity to Staphylococcus sp. (Table 3). The MICs of the C-Lys to S. aureus were 0.07-4.74 $\mu \mathrm{M}$. It was found that mutants $127 \mathrm{~A}$ and $127 \mathrm{~A} 232 \mathrm{Q}$ had the increased activity with the MIC of $0.07-0.3 \mu \mathrm{M}$ to $S$. aureus, and the antibiotic ampicillin was inferior to rLys and Lys. Additionally, the C-Lys showed low activity (MIC $>4.74 \mu \mathrm{M}$ ) to S. epidermidi CICC 10294, and the $127 \mathrm{~A}$ and $127 \mathrm{~A} 232 \mathrm{Q}$ had very high activity with the MIC of $0.15 \mu \mathrm{M}$. However, compared with parental Lys, the mutants of 126P, 126P232Q, 125Q, 125Q232Q had lower activity to S. aureus CICC 10436, S. epidermidis CICC 10294 and S. sciuri 26. Due to the excellent activity of mutants $127 \mathrm{~A}$ and $127 \mathrm{~A} 232 \mathrm{Q}$, and there was no glycosylation in the preparation stage, they were selected for the further study.

\section{Expression of 127A and 127A232Q in Fermentor Level}

Transformants of 127A, 127A232Q and Lys were cultured and induced in $5-\mathrm{L}$ fermentor at $29^{\circ} \mathrm{C}$ via high-density cultivation, respectively. The activity was detected after $24 \mathrm{~h}$ of induction and the total protein level increased with the inducing time. It is found that the mutants had the best activity during $48-72 \mathrm{~h}$ of induction (Figure 4A). After $72 \mathrm{~h}$ of fermentation, the total protein content of 127A, 127A232Q, and Lys were 1315, 1141, and $1631 \mathrm{mg} / \mathrm{L}$, respectively (Figures $\mathbf{4 B}, \mathrm{C}$ ), and the cell wet weight increased to with the extension of the induction time (Figure 4D).

\section{rLys/Lys Purification}

The fermentation broth was centrifuged at $5000 \mathrm{rpm}$ for $30 \mathrm{~min}$ and the supernatant was collected and filtered with $0.45 \mu \mathrm{m}$ filtration. The membrane-packed dialysis was used to remove the salt to the conductivity of the supernatant was below $2 \mathrm{us} / \mathrm{cm}$, and target proteins were purified with a cation-exchange column. The SDS-PAGE confirmed that purified product with the single band (Figure 5A). The product was freeze-dried a for further studied.

\section{Deglycosylation Experimental}

127A, 127A232Q and Lys were subjected to deglycosylation experiment to confirm whether the variants were nonglycosylated and the additional upper band in SDS-PAGE of Lys was glycosylated (Figure 5A) from side chain of glycosylation. As shown in Figure 5B, the only band of 127A and 127A232Q has not changed, and showing the same weight as $127 \mathrm{~A}$ control. The upper band corresponding for the glycolysated Lys disappeared, only the lower band was left. In general, the result indicated that the upper bands of Lys are glycosylated, while rLys is non-glycosylated.

\section{Time-Kill Assay of rLys/Lys}

The time-killing kinetics showed that rLys/Lys exhibited effective antimicrobial activity against $S$. aureus ATCC 43300 in vitro (Figure 6). The rLys/Lys had significant advantages in antimicrobial activity and sterilization speed compared with ampicillin. For $1 \times$ MIC, $2 \times$ MIC, $4 \times$ MIC of 127A, 127A232Q, Lys, and C-Lys treatment groups, the bacteria were almost completely killed within 30 minutes. There was no regrowth except the $1 \times$ MIC of 127A in $24 \mathrm{~h}$. However, for ampicillin treatment group, the $\log _{10}(\mathrm{CFU} / \mathrm{mL})$ of $S$. aureus decreased to 2.5 to 3.5 within $1.5 \mathrm{~h}$. While the bacteria slowly recovered and regrew in 2 to $10 \mathrm{~h}$ in 1 and $2 \times$ MIC of ampicillin.

\section{Synergism Assays}

The drug combination assay was applied to detect the synergism against pathogenic bacteria (Table 4). 127A, 127A232Q, Lys and C-Lys were observed in combination with four antibacterial drugs (ampicillin, kanamycin, nisin, and ciprofloxacin) with different mechanisms against S. aureus ATCC 43300. The combination of 127A with the four antibiotics showed FICI values of $1.125,1,1,1.0625$, respectively; and the FICI indexes between $127 \mathrm{~A} 232 \mathrm{Q}$ and the four antibiotics were $1.0625,1,1,1.0625$, respectively. According to the synergy 

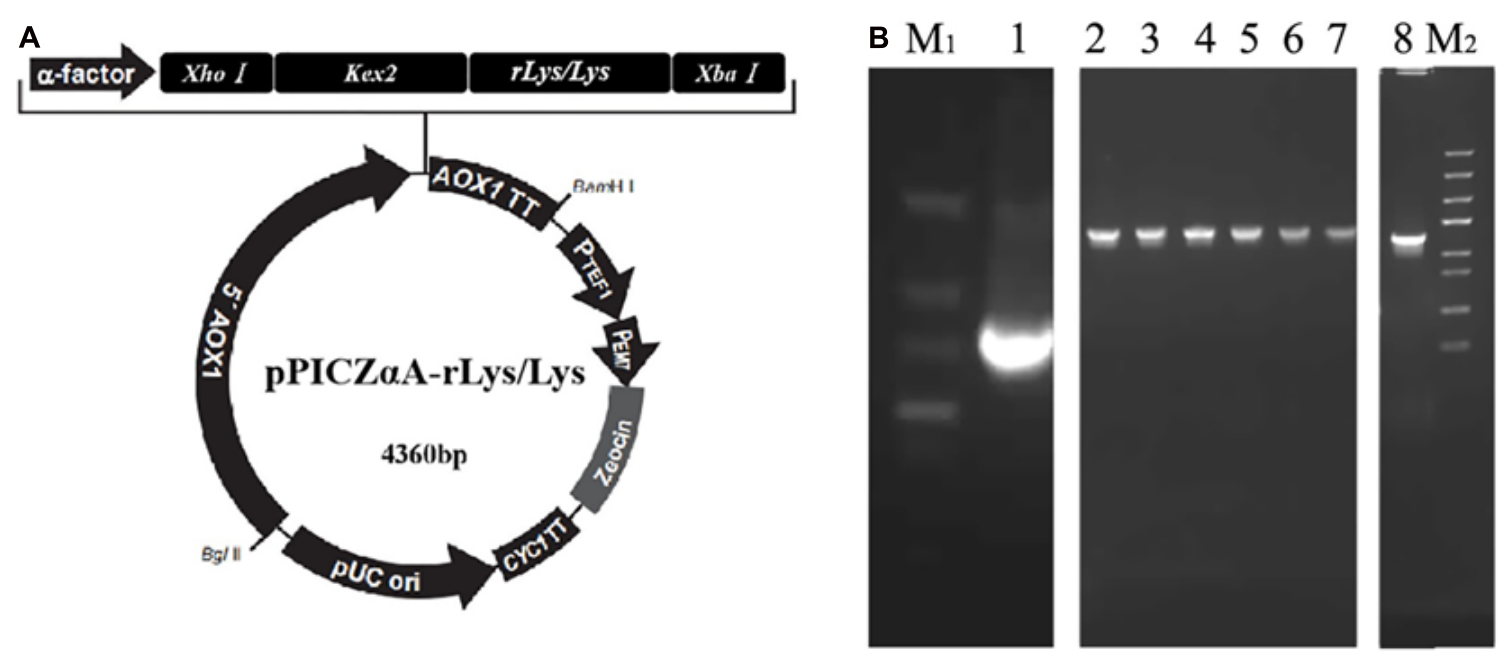

FIGURE 2 | Construction of the pPICZ $\alpha A$-rLys/Lys plasmid. (A) The schematic diagram of the pPICZ $\alpha$ A-rLys/Lys expression vector. (B) PCR products of the rLys/Lys. Line M1 and M2, DNA lander Marker II and Trans 5K Marker; line 1-8, the PCR products of 126P, 126P 232Q, 127A, 127A232Q, 125Q, 232Q, 125232Q.

index, it was found that all lysostaphins or non-glycosylation engineered enzymes had additive and indifference effects with the four antibiotics.

\section{Cytotoxicity and Selectivity Index}

The cytotoxicity of rLys, Lys, C-Lys was evaluated by measuring the cell viability of lysostaphins treated mouse RAW264.7 cells. As shown in Figure 7A, with the increasing concentration of lysostaphin, the cell viability decreased slightly. When exposed to $128 \mu \mathrm{g} / \mathrm{mL}$ of $127 \mathrm{~A}, 127 \mathrm{~A} 232 \mathrm{Q}$, Lys, and C-Lys, the cell viability were $91.1,83.1,87.1$, and $82.8 \%$, respectively. And the viability of cells was higher than $90 \%$ at lower concentrations of the lysostaphins with the concentration of $1-64 \mu \mathrm{g} / \mathrm{mL}$. The results suggested that lysostaphins had low cytotoxicity against RAW264.7 cells. To determine the safe range of drug effect, the SI values should be higher than 10 . The higher selectivity index of 127A and 127A232Q (SI = 101.2 and 1567.3) (Supplementary Table 1) encouraged us study further.

\section{Hemolysis}

The hemolytic assay mainly detects whether the peptide is toxic to the red blood cell. As shown in Figure 7B, only C-Lys has the highest concentration at $1280 \mu \mathrm{g} / \mathrm{mL}$. Red blood cells have no organelles, and the main barrier is the cell membrane. The hemolytic experiment fully verified that the lysostaphins did not damage the cell membrane, having the security in blood.

\section{Effect of pH and Temperature on the Activity of rLys and Lys}

The $\mathrm{pH}$ and thermal stability of rLys/Lys were shown in Table 5. rLys/Lys displayed strong stability in different $\mathrm{pH}$ values from 2.0 to 8.0 against $S$. aureus, and the activity of 127A and 127A232Q lightly reduced in the alkaline environment ( $\mathrm{pH}$ 10.0). Meanwhile, it was found that the temperature has a great influence on lysostaphin. The activity of rLys, Lys,
C-Lys remained unchanged in the temperature range from $20-60^{\circ} \mathrm{C}$, after exposure to $80^{\circ} \mathrm{C}$ and $100^{\circ} \mathrm{C}$, the MIC values of 127A increased 3.9 and 31.6 folds, 127A232Q increased 7.9 and 31.6 folds.

\section{Efficacy of rLys/Lys in vivo}

Absolute Lethal Dose of S. aureus ATCC 546 to Mice

After intraperitoneal injection $S$. aureus ATCC 546 (Figure 8A), the mice of low-dose injection groups $\left(1 \times 10^{7}, 1 \times 10^{8} \mathrm{CFU} / \mathrm{mL}\right)$ were alive within $72 \mathrm{~h}$. The mice of high-dose injection groups showed typical symptoms of infection: eyes secreted mucus, smaller eyelid opening, the body temperature increased, and severe shivered and shaked. The survival rate of mice injected with $5 \times 10^{8}, 1 \times 10^{9} \mathrm{CFU} / \mathrm{mL}$ S. aureus were $40 \%$ and $80 \%$, respectively. When the challenge dose of $S$. aureus was $5 \times 10^{9}, 1 \times 10^{10} \mathrm{CFU} / \mathrm{mL}$, all mice died within 6 hours. Therefore, $5 \times 10^{9} \mathrm{CFU} / \mathrm{mL}$ of $S$. aureus was determined as the absolute lethal dose.

\section{The Therapeutic Effect of rLys, Lys, C-Lys}

After intraperitoneal injection of the absolute lethal dose of S. aureus ATCC 546, the mice were treated with different concentrations of lysostaphin by intraperitoneal injection. The survival rates of the mice were shown in Figure 8B. All of the mice in untreated group died within $24 \mathrm{~h}$. Although $10 \mathrm{mg} / \mathrm{kg}$ Ampicillin failed to improve the survival rate, it prolonged the survival time of the mice. And the $5 \mathrm{mg} / \mathrm{kg}$ Lys, $10 \mathrm{mg} / \mathrm{kg}$ Lys, $5 \mathrm{mg} / \mathrm{kg}$ C-Lys, and $20 \mathrm{mg} / \mathrm{kg}$ Ampicillin can make the survival

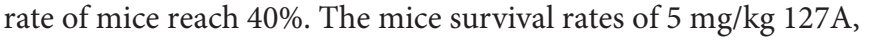
$5 \mathrm{mg} / \mathrm{kg}$ 127A232Q and $10 \mathrm{mg} / \mathrm{kg}$ C-Lys treatment groups were up to $80 \%$, and they had the similar therapeutic effects. $127 \mathrm{~A}$ and $127 \mathrm{~A} 232 \mathrm{Q}$ at a concentration of $10 \mathrm{mg} / \mathrm{kg}$ had the best effect which can make all mice survive. It's demonstrated that lysostaphin showed a good therapeutic effect, which at the same 
A
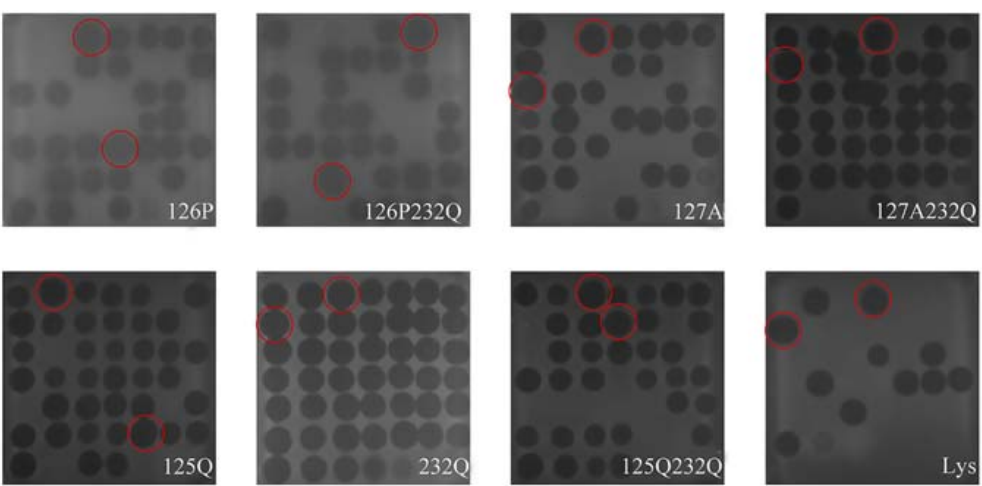

B
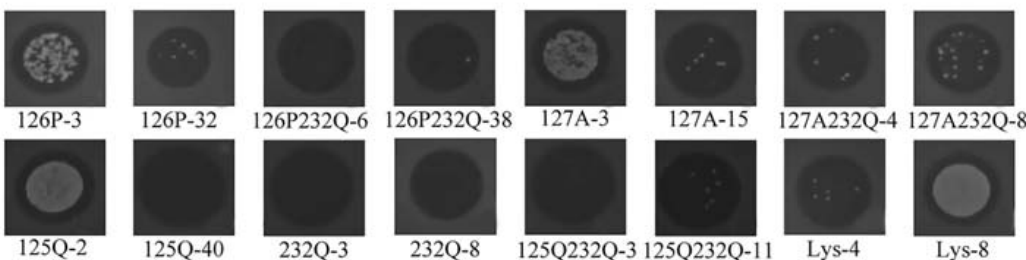

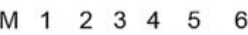
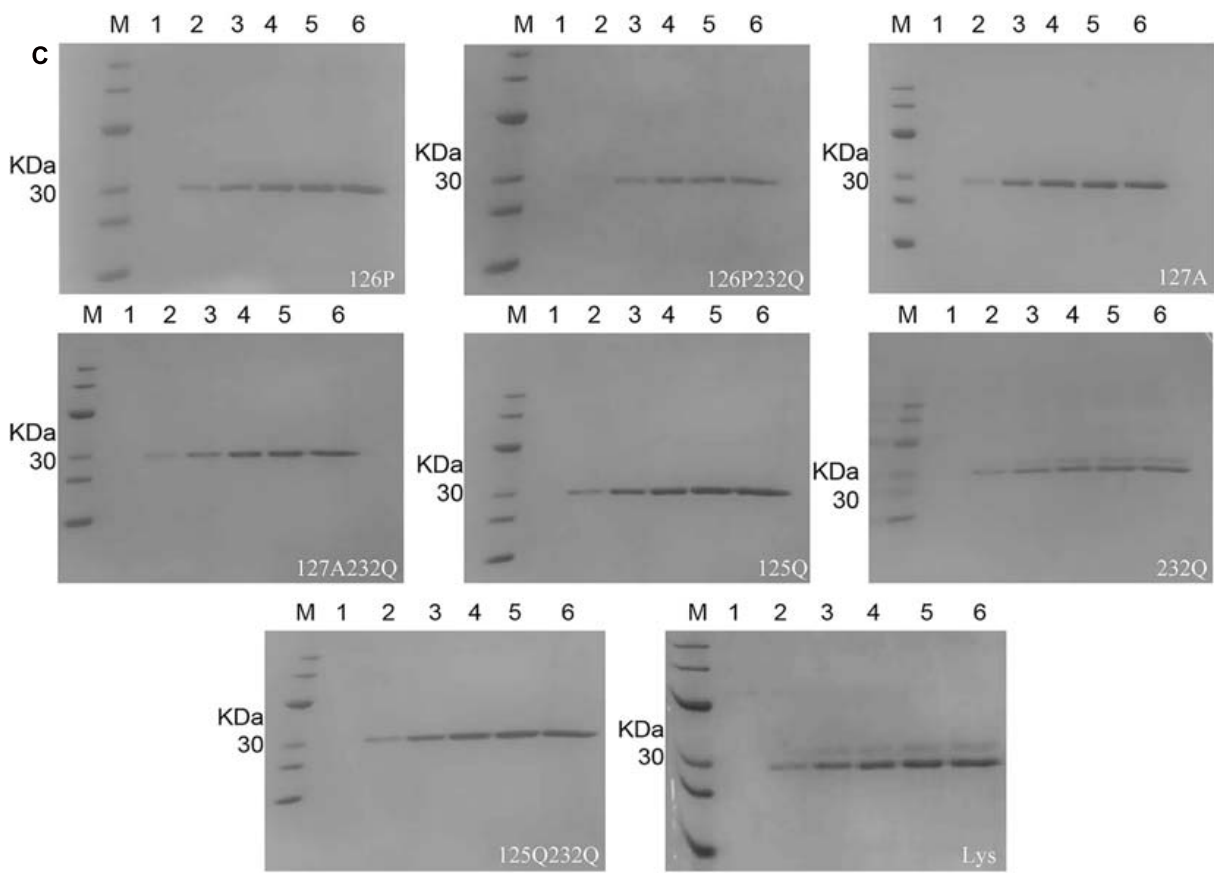

FIGURE 3 | Expression of rLys/Lys in P. pastoris X-33 at the shaking flask level. The inhibition zones of rLys/Lys fermentation supernatants in (A) 48-well plates and (B) 1-L shake flasks. The superior transformants was emphasized by the red circles. (C) SDS-PAGE analysis of rLys/Lys fermentation supernatants in 1-L shake flasks. M, The molecular mass standards of Ruler I; line 1 6, fermentation supernatants of rLys/Lys $(10 \mu \mathrm{L})$ taken at 0, 24, 48, 72, 96 , and 120 h of induction, respectively.

time, its drug efficacy was more remarkable than that of antibiotic treatment group.

\section{The Effect of rLys, Lys, C-Lys on the Bacterial Load}

The bacterial loads were counted in different organs. As shown in the Figures 8C-F, blood, liver, kidney and spleen were taken at $24 \mathrm{~h}$ post-treatment with $10 \mathrm{mg} / \mathrm{kg}$ rLys, Lys and C-Lys. The bacteria in blood were almost completely eliminated after treatment with 127A, 127A232Q and C-Lys, however, there are still had about $5 \log$ CFU after treatment with Amp. The bacteria of each examined organ of liver, kidney and spleen showed 5-7 $\log$ CFU reduction, and the bacterial load had all been reduced by $99.99 \%$. In general, all lysostaphins show highly bactericidal activity in various tissues. 
TABLE 3 | The MIC values of rLys/Lys.

\begin{tabular}{|c|c|c|c|c|c|c|c|c|c|c|}
\hline \multirow[t]{2}{*}{ Strain } & \multicolumn{10}{|c|}{ MIC $(\mu \mathrm{M})$} \\
\hline & $126 P$ & 126P232Q & $127 A$ & 127A232Q & $125 Q$ & $125232 Q$ & $232 Q$ & Lys & C-Lys & Amp \\
\hline S. aureus ATCC 25923 & 0.30 & 0.30 & 0.15 & 0.30 & 0.30 & 0.15 & 0.15 & 0.15 & 0.30 & $<0.31$ \\
\hline S. aureus ATCC 43300 & 0.15 & 0.07 & 0.15 & 0.15 & 0.30 & 0.30 & 0.15 & 0.15 & 0.07 & 4.96 \\
\hline S. aureus CICC 10436 & 1.19 & 1.19 & 0.30 & 0.30 & 4.74 & 4.74 & 0.15 & 0.59 & 4.74 & 1.24 \\
\hline S. aureus CICC 10473 & 0.15 & 0.30 & 0.15 & 0.15 & 0.30 & 0.15 & 0.15 & 0.15 & 0.15 & 1.24 \\
\hline S. aureus CICC 21601 & 0.15 & 0.15 & 0.15 & 0.15 & 0.15 & 0.15 & 0.30 & 0.15 & 0.15 & $<0.31$ \\
\hline S. aureus CVCC 546 & 0.15 & 0.30 & 0.15 & 0.15 & 0.30 & 0.15 & 0.15 & 0.15 & 0.15 & $<0.31$ \\
\hline S. aureus FRI-GEL160701 & 0.15 & 0.30 & 0.15 & 0.15 & 0.30 & 0.30 & 0.15 & 0.15 & 0.15 & $<0.31$ \\
\hline S. aureus FRI-GEL180901 & 0.15 & 0.30 & 0.07 & 0.15 & 0.15 & 0.15 & 0.07 & 0.15 & 0.59 & 2.48 \\
\hline S. epidermidis CGMCC 1.4206 & 0.30 & 0.15 & 0.15 & 0.15 & $>4.74$ & 4.74 & 0.15 & 0.15 & 0.30 & 2.48 \\
\hline S. epidermidis CICC 10294 & 4.74 & 4.74 & 0.30 & 0.30 & $>4.74$ & 0.59 & 0.30 & 2.37 & $>4.74$ & 4.96 \\
\hline S. hyicus NCTC 10350 & 0.15 & 0.15 & 0.07 & 0.07 & 0.15 & 0.15 & 0.07 & 0.15 & 0.15 & 79.40 \\
\hline S. hyicus ACCC 61734 & 0.07 & 0.15 & 0.07 & 0.07 & 0.15 & 0.15 & 0.07 & 0.07 & 0.07 & 9.93 \\
\hline S. sciuri FRI-GEL180902 & 0.59 & 0.59 & 0.30 & 0.59 & 0.59 & 0.59 & 0.59 & 0.30 & 0.30 & $<0.31$ \\
\hline S. sciuri FRI-GEL180903 & 0.15 & 0.30 & 0.15 & 0.15 & 0.15 & 0.15 & 0.15 & 0.15 & 2.37 & 2.48 \\
\hline
\end{tabular}
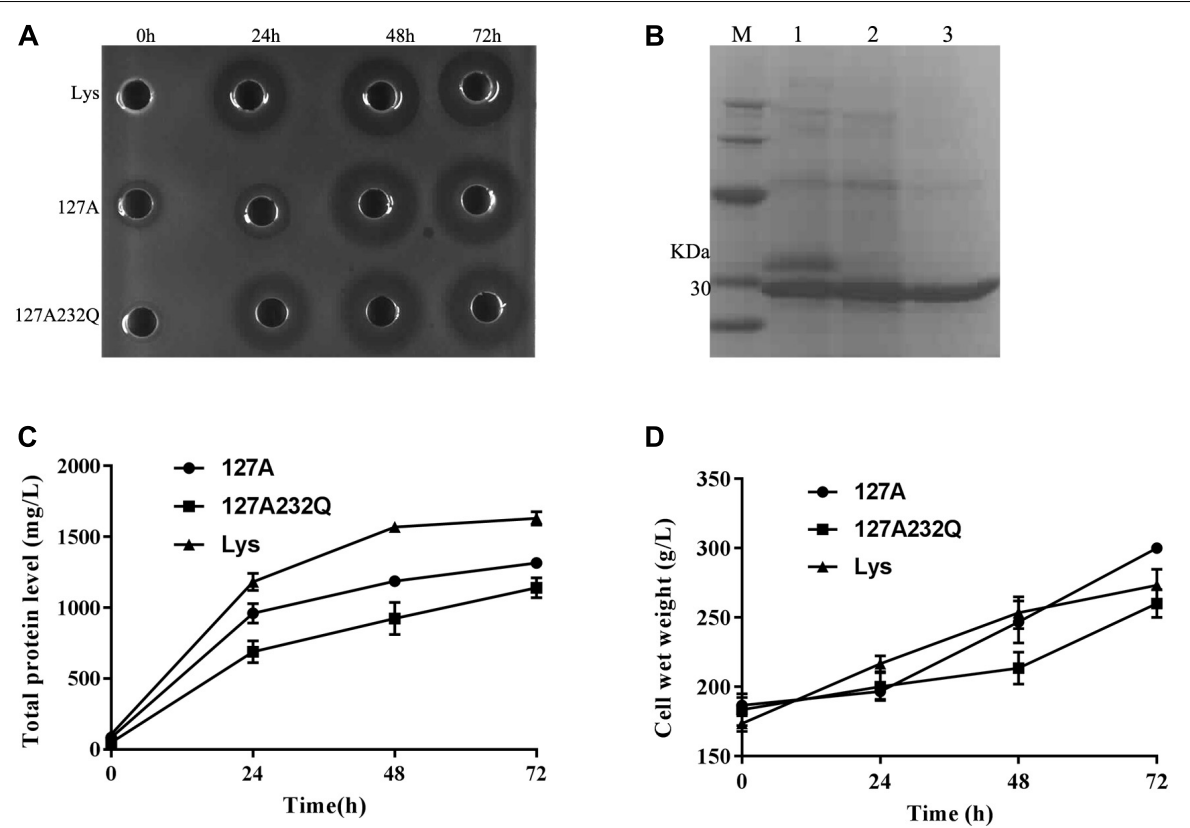

FIGURE 4 | High-density cultivation of rLys/Lys in the fermentor level. (A) The inhibition zones of 127A, 127A232Q and Lys fermentation supernatants with different induced time against S. aureus ATCC 43300; (B) SDS-PAGE analysis of Lys, 127A and 127A232Q fermentation supernatants at 72 h. M, The molecular mass standards of Ruler I; line 1 3, The fermentation supernatant of Lys, 127A and 127A232Q; (C) Time curves of the total secreted protein levels in the high-density fermentation; (D) Time curves of the cell wet weights in the high-density fermentation.

\section{Histopathological Observation}

Since $10 \mathrm{mg} / \mathrm{kg}$ lysostaphin can provide a higher survival rate of mice, the HE staining analysis of each tissue of the mice treated with this dose drug was performed. The kidney and spleen of uninfected mice have no pathological symptoms (Figure 9A). In the untreated infection group (Figure 9B), the local renal tissue interstitium was infiltrated with scattered inflammatory cells. A large area of renal tubules was atrophy and degeneration with obvious local inflammation. A small amount of glomerular atrophy was observed at the obvious local inflammatory sites and the tissue section was scored as "very severe" (Table 2). The red pulp of the spleen tissue of the untreated infection mice was congested, the white pulp volume relatively increased, the splenic nodules were enlarged, the center of occurrence was obvious, the marginal zone was clearly visible, and obviously enlarged, the splenic cord atrophy, disappeared locally, and a large number of splenic sinuses red blood cells, splenic cord lymphocytes were depleted and the tissue section was scored as "very severe."

After treatment with 127A, 127A232Q, C-Lys, Lys and ampicillin, the kidney tissue showed obvious recovery. 

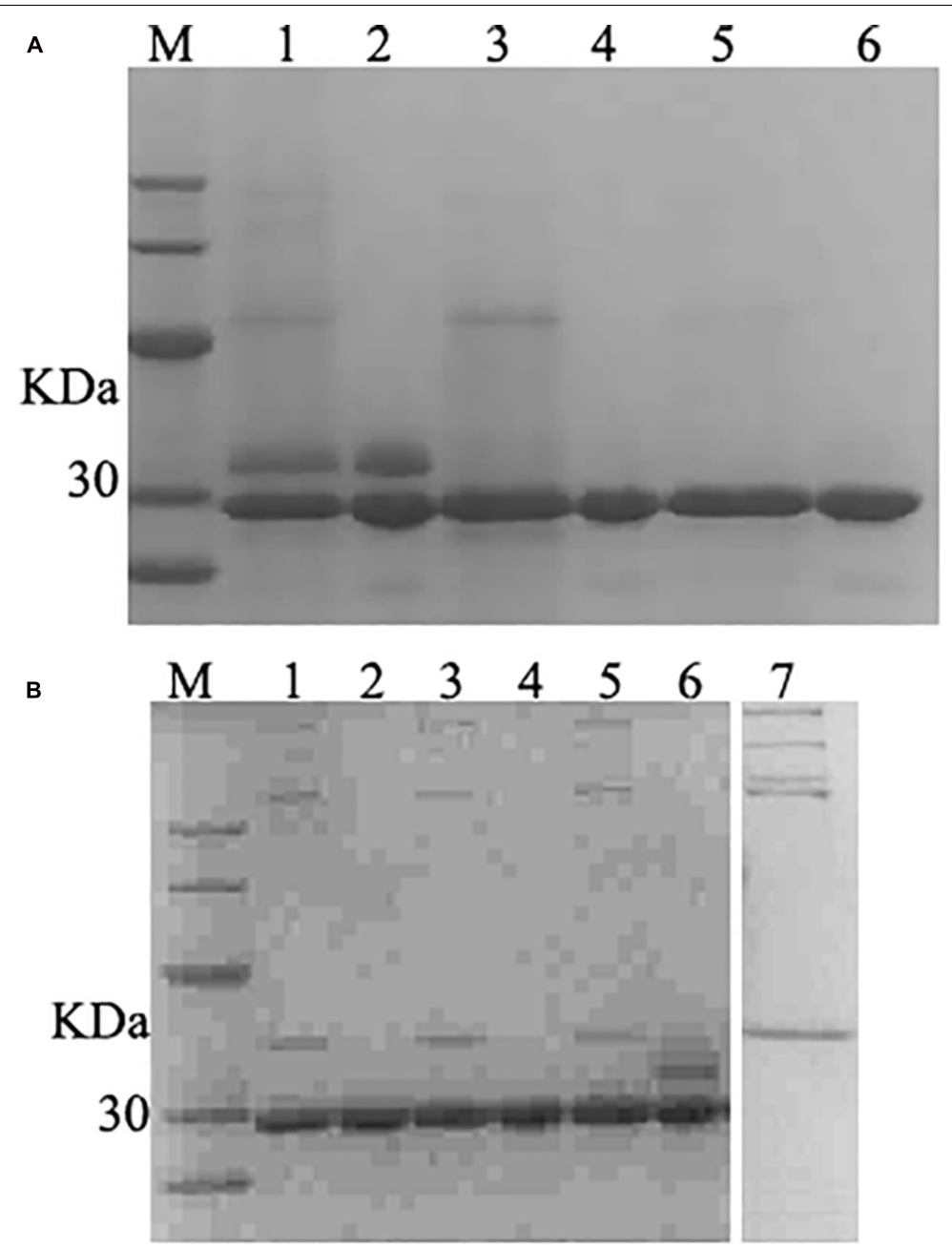

FIGURE 5 | SDS-PAGE analysis of purified and deglycosylated rLys/Lys. (A) SDS-PAGE analysis of purified rLys/Lys. M, The molecular mass standards of Ruler I. Line 1, 3, 5, fermentation supernatants of Lys, 127A and 127A232Q; line 2, 4, 6, the purified target peak of Lys, $127 \mathrm{~A}$ and $127 \mathrm{~A} 232 \mathrm{Q}(10 \mu \mathrm{L})$, respectively.

(B) SDS-PAGE analysis of deglycosylation experiment. M, The molecular mass standards of Ruler I. Line 1,3,5, the deglycosylation of 127A, 127A232Q, Lys; Line 2,4,6, 127A, 127A232Q, Lys negative control (with no enzyme of deglycosylated protease); line 7, the control of deglycosylated protease.

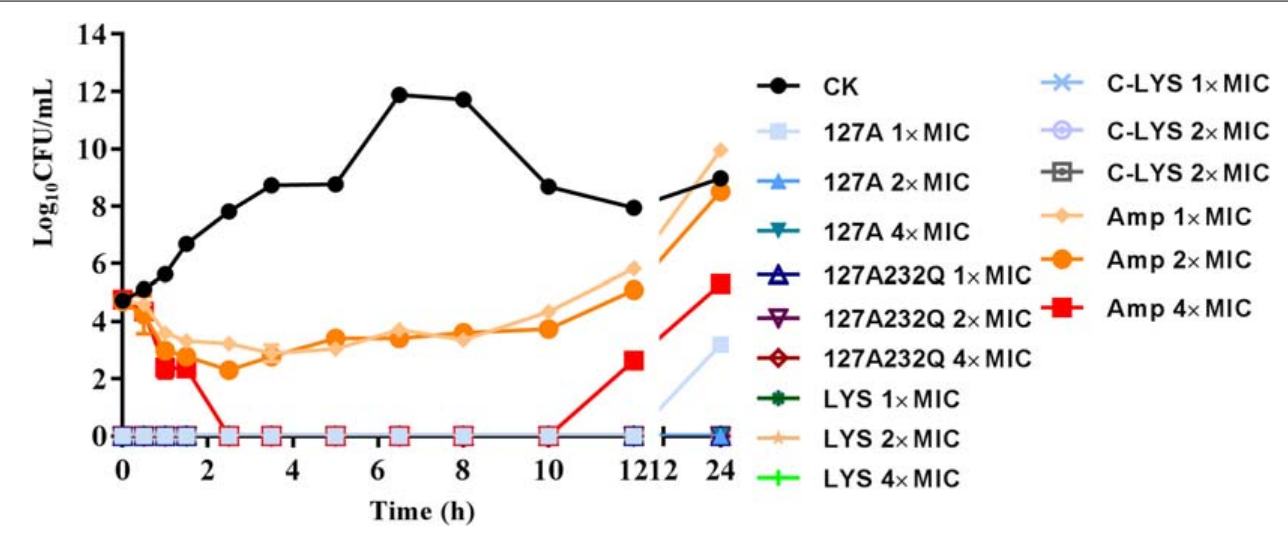

FIGURE 6 | The time-killing curves of 127A, 127A 232Q, Lys and C-Lys against S. aureus ATCC 43300 in vitro. Ampicillin was used as the positive, CK: S. aureus ATCC 43300 were incubated in the presence of medium alone. 
TABLE 4 | Combination effects of 127A, 127A232Q, Lys, C-Lys with antibiotics.

\begin{tabular}{|c|c|c|c|c|c|}
\hline \multirow[t]{2}{*}{ Combination } & \multirow[t]{2}{*}{ Variety } & \multicolumn{4}{|c|}{ S. aureus ATCC 43300} \\
\hline & & $\mathrm{MIC}_{\mathrm{a}}$ & $\mathrm{MIC}_{\mathrm{c}}$ & FIC & $\mathrm{FICl}$ \\
\hline \multirow[t]{2}{*}{ 127A-Amp } & $127 \mathrm{~A}$ & 0.07 & 0.01 & 0.125 & 1.125 \\
\hline & Amp & 2.48 & 2.48 & 1 & \\
\hline \multirow[t]{2}{*}{ 127A-Kan } & $127 \mathrm{~A}$ & 0.07 & 0.04 & 0.5 & 1 \\
\hline & Kan & 132.23 & 66.12 & 0.5 & \\
\hline \multirow[t]{2}{*}{ 127A-Nisin } & $127 \mathrm{~A}$ & 0.07 & 0.04 & 0.5 & 1 \\
\hline & Nisin & 36.57 & 18.29 & 0.5 & \\
\hline \multirow[t]{2}{*}{ 127A-Сip } & $127 \mathrm{~A}$ & 0.07 & 0.004 & 0.0625 & 1.0625 \\
\hline & Cip & 0.76 & 0.76 & 1 & \\
\hline \multirow[t]{2}{*}{ 127A 232Q-Amp } & $127 \mathrm{~A} 232 \mathrm{Q}$ & 0.15 & 0.01 & 0.0625 & 1.0625 \\
\hline & Amp & 2.48 & 2.48 & 1 & \\
\hline \multirow[t]{2}{*}{ 127A 232Q-Kan } & $127 A 232 Q$ & 0.15 & 0.07 & 0.5 & 1 \\
\hline & Kan & 132.23 & 66.12 & 0.5 & \\
\hline \multirow[t]{2}{*}{ 127A 232Q-Nisin } & $127 \mathrm{~A} 232 \mathrm{Q}$ & 0.15 & 0.07 & 0.5 & 1 \\
\hline & Nisin & 36.57 & 18.29 & 0.5 & \\
\hline \multirow[t]{2}{*}{ 127A 232Q-Сip } & $127 \mathrm{~A} 232 \mathrm{Q}$ & 0.15 & 0.01 & 0.0625 & 1.0625 \\
\hline & Сip & 0.76 & 0.76 & 1 & \\
\hline \multirow[t]{2}{*}{ Lys-Amp } & Lys & 0.15 & 0.07 & 0.5 & 1 \\
\hline & Amp & 2.48 & 1.24 & 0.5 & \\
\hline \multirow[t]{2}{*}{ Lys-Kan } & Lys & 0.15 & 0.07 & 0.5 & 1 \\
\hline & Kan & 132.23 & 66.12 & 0.5 & \\
\hline \multirow[t]{2}{*}{ Lys-Nisin } & Lys & 0.15 & 0.07 & 0.5 & 1 \\
\hline & Nisin & 36.57 & 18.29 & 0.5 & \\
\hline \multirow[t]{2}{*}{ Lys-Cip } & Lys & 0.15 & 0.01 & 0.0625 & 1.0625 \\
\hline & Сip & 0.76 & 0.76 & 1 & \\
\hline \multirow[t]{2}{*}{ C-Lys-Amp } & C-Lys & 0.15 & 0.02 & 0.125 & 1.125 \\
\hline & Amp & 2.48 & 2.48 & 1 & \\
\hline \multirow[t]{2}{*}{ C-Lys-Kan } & C-Lys & 0.15 & 0.07 & 0.5 & 1 \\
\hline & Kan & 132.23 & 66.12 & 0.5 & \\
\hline \multirow[t]{2}{*}{ C-Lys-Nisin } & C-Lys & 0.15 & 0.07 & 0.5 & 1 \\
\hline & Nisin & 36.57 & 18.29 & 0.5 & \\
\hline \multirow[t]{2}{*}{ C-Lys-Cip } & C-Lys & 0.15 & 0.01 & 0.0625 & 1.0625 \\
\hline & Cip & 0.76 & 0.76 & 1 & \\
\hline
\end{tabular}

$\overline{M I C}$, the MIC of variety drug alone (including Lys, rLys and antibiotic alone); $M I C_{C}$, the MIC of the most effective combination. Amp, Ampicillin; Kan, Kanamycin; Ciprofloxacin.

The therapeutic effect of the drug was evaluated as: $127 \mathrm{~A}>127 \mathrm{~A} 232 \mathrm{Q}=\mathrm{C}$-Lys $>$ Lys $=$ Amp. In 127A treatment group, kidney tissue was recovered almost the same as normal within $24 \mathrm{~h}$. And the Lys, which was the least effective group, also could relieve symptoms, with local inflammatory cell infiltration, renal tubular atrophy, and the disappearance of glomerular involvement. In the spleen tissue of the treatment group, the drug treatment effect was evaluated as: $127 \mathrm{~A}=127 \mathrm{~A} 232 \mathrm{Q}=\mathrm{C}$ Lys $>$ Amp $>$ Lys. Among them, 127A can make the symptom score reach the "mild symptom" level.

\section{DISCUSSION}

Glycosylation is the process of adding sugars to proteins or lipids under the control of enzymes which starting at the endoplasmic reticulum and ending at the Golgi apparatus (Zhang et al., 2019). There are 5 kinds of glycosylation, including $\mathrm{N}$-glycosylation, O-glycosylation, and the rarely ones such as C-glycosylation, S-glycosylation and P-glycosylation (Eichler, 2019). Among them, N-glycosylation is the process that the sugar chains connect to the free $-\mathrm{NH}_{2}$ group of the specific asparagine (NXS/T, $\mathrm{X}$ indicates any amino acid except proline) in the nascent peptide chain (Marshall, 1974; Bause and Hettkamp, 1979; Han et al., 2020); O-glycosylation is the process that the carbon chains transfer to the oxygen atom of the hydroxyl group of serine, threonine or hydroxylysine in the polypeptide chain, and its glycosylation positions are highly selective (Stavenhagen et al., 2019; Wells and Feizi, 2019). In this study, there are two N-glycosylation sites at 125 (NST) and 232 (NKS). These two sites of amino acids were modified with similar amino acid residue Q. Meanwhile, because of the key role of $125 \mathrm{~N}$ at the C-terminal end of the catalytic domain, the mutants of $126 \mathrm{~S}$ and $127 \mathrm{~T}$ were also designed. The result showed that the mutants of $125 \mathrm{Q}$ could remove the glycosylation effectively, while the mutant of 232Q could not (Figure 3). It was found that the $\mathrm{N}$-glycosylation efficiency was decreased within 60 AA of the C-terminus (Nilsson and von Heijne, 2000). The distance from the $232 \mathrm{~N}$ site to the C-terminus of lysostaphin is only 14 residues, which leading to the inefficient glycosylation in this position (Figure 3C). Additionally, the N-glycosylation frequency was high when the \pm 1 site of the glycosylation was $S$. The \pm 1 sites of $125 \mathrm{~N}$ in lysostaphin were both $\mathrm{S}$, and the \pm 1 sites of $232 \mathrm{~N}$ were $\mathrm{K}$ and $\mathrm{W}$. The sequence of the $\mathrm{N}$-glycosylation sites in lysostaphin suggesting that $125 \mathrm{~N}$ is a favorable glycosylation site of recombinant lysostaphin in eukaryotic $P$. pastoris expression system (Hamby and Hirst, 2008).

Seven modified rLys (126P, 126P232Q, 127A, 127A232Q, 125Q, 232Q, 125232Q) were obtained by $P$. patoris expression. Compared with all of the MICs of rLys, the result showed that the MIC values of $125 \mathrm{Q}$ was slightly higher than the other rLys (1-4 times) against S. aureus, S. epidermidis and S. hyicus. Zhao et al. (2014) also concluded that lysozyme activity was reduced by replacing the $\mathrm{N}$-amino acid at position 125 with Gln. Although no relevant reference has investigated the role of loop at 125 amino acids in the Lys structure (Sabala et al., 2014; Tossavainen et al., 2018), the results demonstrated that the conserved site at position 125 has an effect on the activity of lysostaphin. In addition, the modified of amino acids on position 126 and 127 (126P, 126P232Q, 127A, 127A232Q) can effectively inhibit the formation of glycosylation and the antimicrobial activity of them were 1-15.8 times improved compared to Lys and C-Lys.

The antibacterial activity of the rLys, Lys and C-Lys was superior to that of ampicillin. Low concentration $(1 \times \mathrm{MIC})$ of 127A, 127A 232Q, Lys, C-Lys can effectively kill S. aureus in few minutes. However, $2 \times$ MIC ampicillin couldn't completely inhibit bacteria, and after treatment with $4 \times \mathrm{MIC}$ ampicillin the bacteria rapidly regrew after $10 \mathrm{~h}$. The rapid bactericidal ability of lysostaphin owed to the character of effective hydrolyze staphylococcal cell wall peptidoglycans. C-terminal cell-wall-targeting domain promotes lysostaphin binding to staphylococcal peptidoglycan (Baba and Schneewind, 1996) and the N-terminal domain with glycylglycine endopeptidase activity 

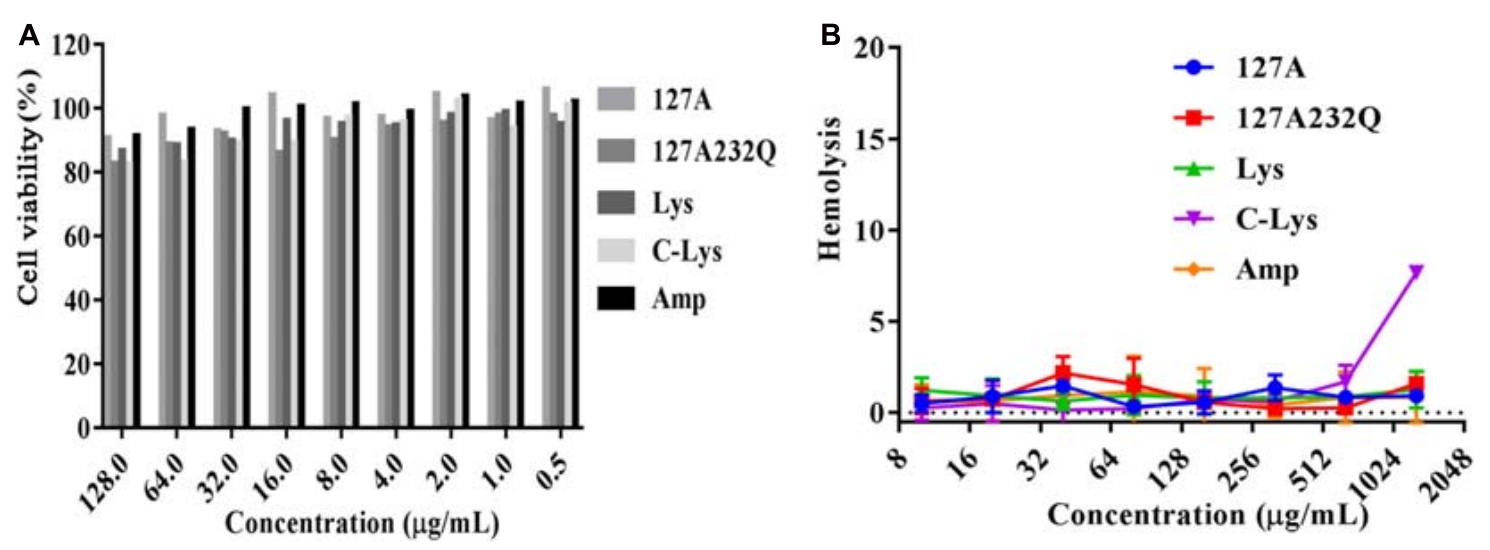

FIGURE 7 | The cytotoxicity and hemolysis of rLys/Lys. (A) Cytotoxicity of 127A, 127A232Q, Lys, C-Lys and Ampicillin against RAW264.7 cells; (B) Hemolytic activity of 127A, 127A232Q, Lys, C-Lys and Ampicillin against fresh mouse red blood cells.

TABLE 5 | The $\mathrm{pH}$ and temperature stability.

$\operatorname{MIC}(\mu \mathrm{M})$

\begin{tabular}{|c|c|c|c|c|c|c|c|c|c|c|c|c|}
\hline & \multicolumn{5}{|c|}{$\mathrm{pH}$} & \multicolumn{7}{|c|}{ Temperature $\left({ }^{\circ} \mathrm{C}\right)$} \\
\hline & 2.0 & 4.0 & 6.0 & 8.0 & 10.0 & 4 & 25 & 40 & 50 & 60 & 80 & 100 \\
\hline $127 A 232 Q$ & 0.15 & 0.15 & 0.15 & 0.15 & 0.30 & 0.15 & 0.15 & 0.15 & 0.15 & 0.15 & 1.19 & 4.74 \\
\hline Lys & 0.15 & 0.15 & 0.15 & 0.15 & 0.15 & 0.15 & 0.15 & 0.15 & 0.15 & 0.15 & 0.30 & 0.59 \\
\hline C-Lys & 0.15 & 0.15 & 0.15 & 0.15 & 0.15 & 0.15 & 0.15 & 0.15 & 0.15 & 0.15 & $>4.74$ & $>4.74$ \\
\hline
\end{tabular}

cleaves pentaglycine cross bridges (Schindler and Schuhardt, 1964). The activity of Lys expressed in $P$. patoris was equivalent or slightly stronger than that of C-Lys expressed in E. coli, this preponderant antimicrobial activity may owe to the $P$. pastoris eukaryotic expression system which could promote the proper folding and reduce protease hydrolysis of exogenous target protein (Yang and Zhang, 2018).

The synergistic activity of 127A, 127A232Q, Lys, C-Lys with various drugs was determined in this study. Due to the complementarity of mechanism, the lysostaphin did not show antagonistic action to various types of drugs. For instance, the ampicillin inhibited the activity of transpeptidase, making it impossible to transpeptidase and peptidoglycan cross-linking inhibiting the formation of cell wall. And ciprofloxacin is a small molecule antibiotic (331 Da) (Park and Strominger, 1957), which entered into bacteria and acted on DNA topoisomerase and inhibited DNA replication (LeBel, 1988). Furthermore, the 127A, 127A232Q, Lys and C-Lys exhibited additive effect with kanamycin and nisin. The bactericidal action of kanamycin and nisin is non-destructive cell wall mechanisms. The kanamycin is binding to $30 \mathrm{~S}$ subunit of bacterial ribosome to inhibit bacterial protein synthesis (Becker and Cooper, 2013; Wargo and Edwards, 2014) and nisin is acting on bacterial membrane to form holes (Montville and Chen, 1998; Chu et al., 2010). Kanamycin and nisin have synergistic effect with bactericides that act on cell walls during bacterial reproduction; it provided evidence for the additive effect of lysozyme and Kanamycin (Chai et al., 2015). Therefore, it is speculated that the probable reason of additive effect is that lysostaphin firstly destroys cell wall, allowing antibiotics further interact with cell membrane or intramembrane macromolecules. Meanwhile, the exact mechanism of synergistic activity for lysostaphin with antibiotics in vitro/vivo should be further study.

Stability is an important index for the production and application of lysostaphin, previous study showed the optimum $\mathrm{pH}$ for the recombinant lysostaphin antimicrobial activity was at 7.0-9.0 (Sharma et al., 2006). In this study, lysostaphin has strong stability at different $\mathrm{pH}$ ranging from 2 to 8 , and the antimicrobial activity was slightly reduced (MIC from 0.15 to $0.3 \mu \mathrm{M}$ ) in alkaline environment ( $\mathrm{pH} 10.0)$. Moreover, the activity of lysostaphin showed stable within $60^{\circ} \mathrm{C}(1 \mathrm{~h}$ treatment). The temperature had less effect on the activity of 127A, 127A232Q and Lys (activity reduced 3.9, 7.9, and 2 times, respectively) than that of C-Lys after $1 \mathrm{~h}$ heat treatment at $80^{\circ} \mathrm{C}$ (activity reduced by 31.6 times). Sharma et al. (2006) indicated that recombinant lysostaphin expressed in E. coli showed low temperature stability $\left(40 \%\right.$ activity lost after $10 \mathrm{~min}$ heat treatment at $\left.60^{\circ} \mathrm{C}\right)$. The difference of temperature stability may be related to the structural stability. The commercial lysostaphin exhibited two melting temperature $\left(\mathrm{Tm}\right.$ : at $47^{\circ} \mathrm{C}$ and $\left.60^{\circ} \mathrm{C}\right)$, and lysostaphin variants S126P and T127A showed a single apparent Tm (Zhao et al., 2014). In consequence, lysostaphin expressed in $P$. pastoris in 

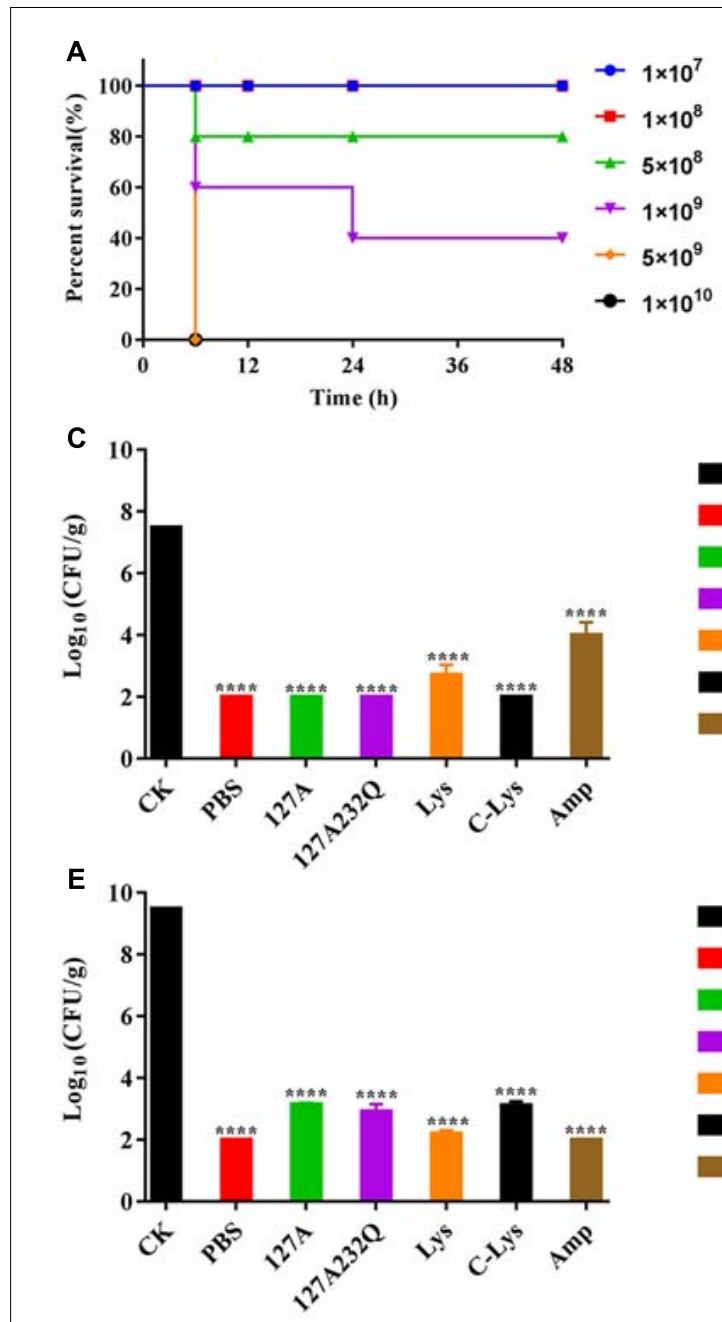
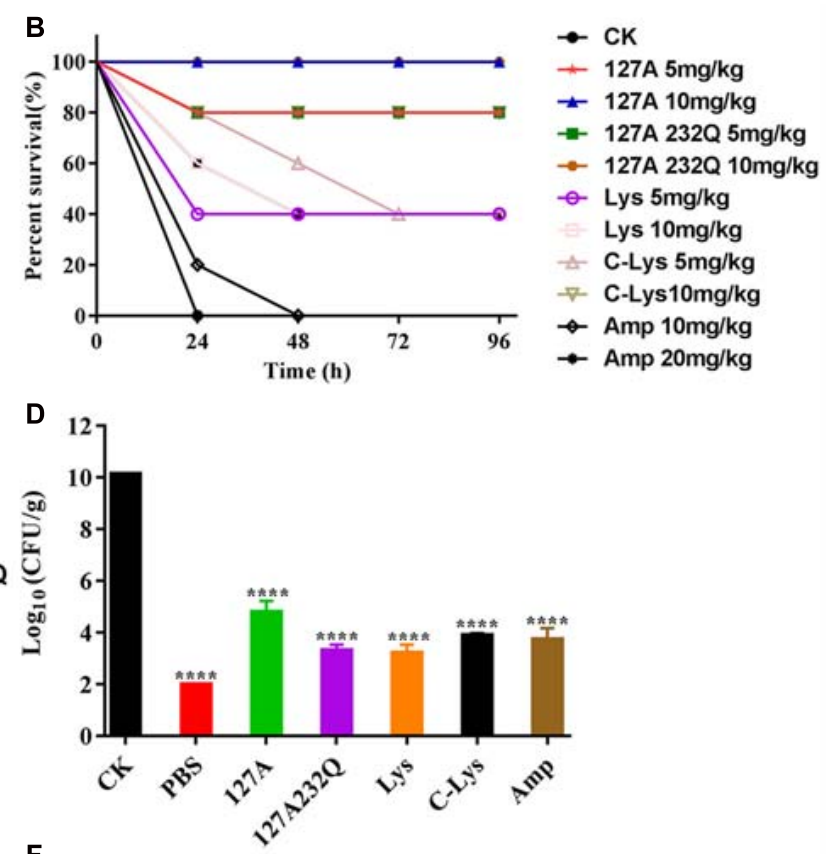

F
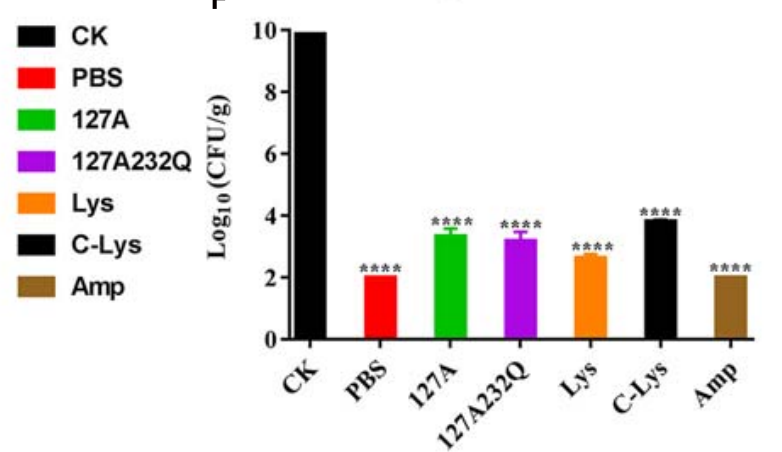

FIGURE 8 | Absolute lethal dose of Staphylococcus aureus CVCC 546 and protection efficacy of rLys/Lys in mice. (A) The absolute lethal dose of S. aureus CVCC 546 to mice. (B) Survival of mice treated with rLys, Lys, C-Lys in S. aureus lethal models. CK: S. aureus injected, untreated. (C-F) Effect of 127A, 127A232Q, Lys, C-Lys and Amp on bacterial burdens of blood, liver, kidney and spleen in S. aureus-infected mice. CK, Untreated infection group; PBS, Uninfected group; Amp, Ampicillin. All data were analyzed by the one-way ANOVA and Bonferroni multiple comparison. ${ }^{* \star \star} p<0.0001$. The results are given as the mean \pm SD $(n=3)$.

this study also displayed higher stability than that of expressed in E. coli (C-Lys).

High virulent $S$. aureus CVCC 546 contains many virulence genes, including $p v l$ (dissolve cell membranes), nuc (Solubilize DNA), sea (cause multiple organ damage), psm-mec (regulate biofilm) (Queck et al., 2009; Kaito et al., 2011) and cna (collagen binding protein) (Supplementary Figure 3), which is easy to cause organ damage and death of animals after infected. Meanwhile, S. aureus CVCC 546 showed multidrug resistant against tetracycline, bacitracin and sulfamethoxazole (Wang et al., 2018), this brings some limitations to antibiotic therapy. In this study, all mice were died after challenged with $5 \times 10^{9} \mathrm{CFU} / \mathrm{mL}$ S. aureus CVCC 546 within $6 \mathrm{~h}$ (Figure 8). 127A, 127A232Q, Lys, and C-Lys administered once a day at $10 \mathrm{mg} / \mathrm{kg}$ can make the survival rate increased to 100,100 , 40 , and $80 \%$, respectively, and significantly clear the amount of S. aureus in spleen (99.99\%) for $23 \mathrm{~h}$ (Figure 8). The $20 \mathrm{mg} / \mathrm{kg}$ ampicillin, administered twice a day at $20 \mathrm{mg} / \mathrm{kg}$, showed only $40 \%$ survival rate, the therapeutic effect was far less than that of lysostaphin. By histological observation (Figure 9), 127A showed the best protective effect on organs, which was consistent with the therapeutic effect.

Previous study has proved that the in vitro short serum halflife period of lysostaphin ( $<1 \mathrm{~h}$ ) (Walsh et al., 2003) did not affect the capacity of lysostaphin in vivo (Kokai-Kun et al., 2007). Lysostaphin not only protected mice from $S$. aureus infection (Kokai-Kun et al., 2007; Chen et al., 2014), but also treated rabbit and dog endocarditis caused by S. aureus (Goldberg et al., 1967). Meanwhile, lysostaphin can also be used as a topical drug for wound infection (Cheleuitte-Nieves et al., 2020). Additionally, studies demonstrated that $\beta$-lactam antibiotics oxacillin and lysostaphin combination could reduce lysostaphin dosage from 5 to $1 \mathrm{mg} / \mathrm{kg}$ for treatment of an MRSA infection (Kiri et al., 2002). In addition, lysostaphin in combination with nisin was effective 

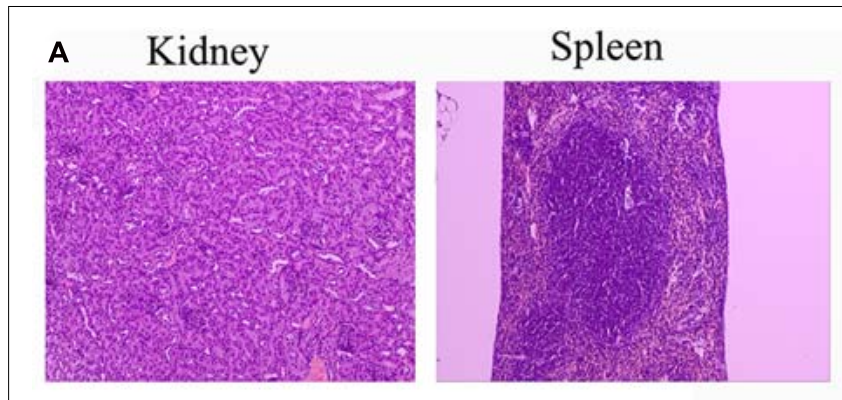

C
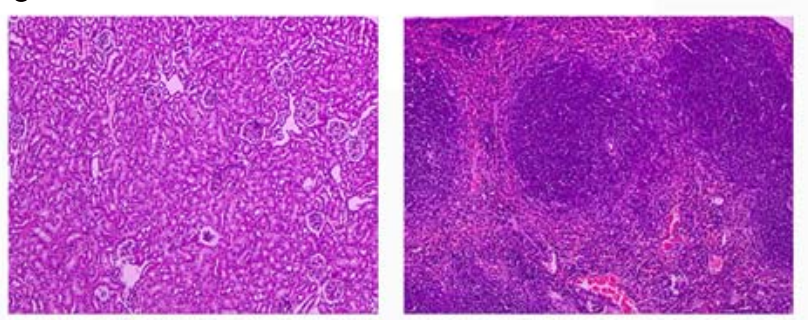

E
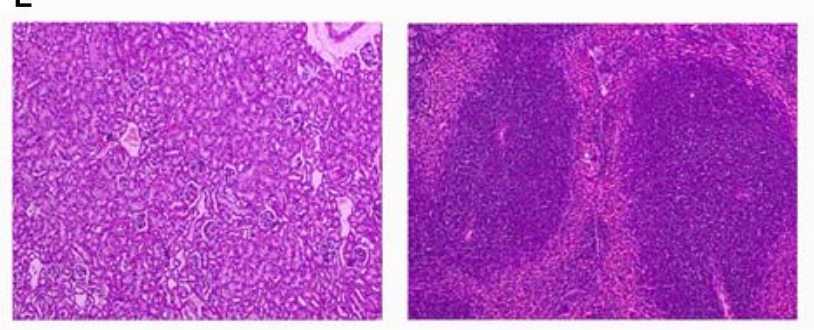

G
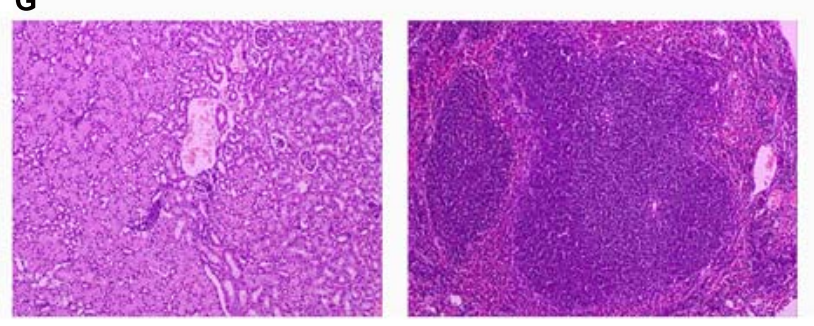

B
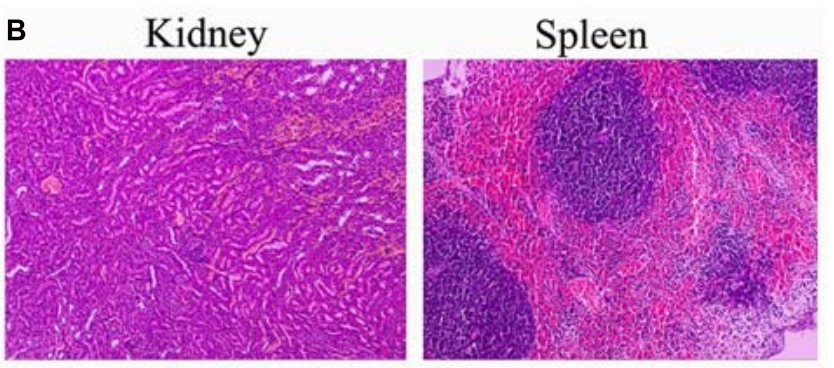

D
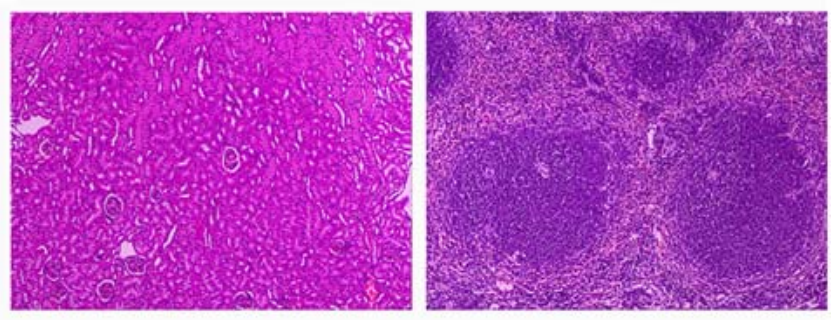

$\mathbf{F}$
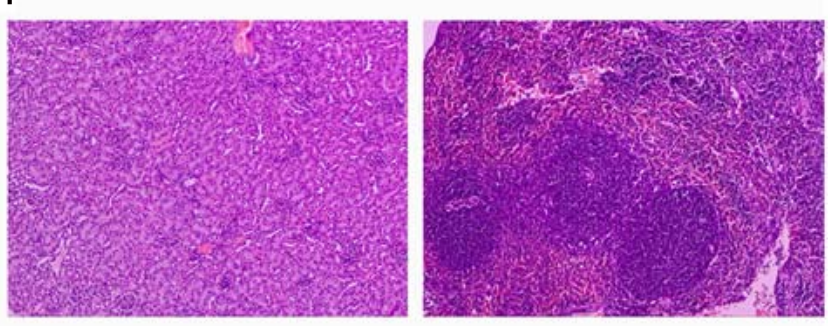

FIGURE 9 | Protection of rLys/Lys against multiple-organ injuries from S. aureus CVCC 546. (A) Uninfected group; (B) Untreated infection group; (C-G) Therapeutic effect of 127A, 127A232Q, Lys, C-Lys and Amp (10 mg/kg) on kidney and spleen injury.

in killing most biofilm of $S$. aureus involved in bovine mastitis (Ceotto Vigoder et al., 2016), the results were consistent with synergy in this study (Table 4). The combination of antibiotics and lysostaphin is superior to the use of a single drug, since it would prevent the possible development of lysostaphin-resistant (Bastos et al., 2015).

In general, the lysostaphin mutants were designed to eliminate the glycosylation during the expression in P. pastoris. In these mutants, 127A and 127A232Q showed the potent antimicrobial activity to $S$. aureus, and they killed MRSA strain ATCC 43300 in very short time (99.9\% killing rate within $30 \mathrm{~min}$ and no regrowth in $24 \mathrm{~h}$ ). The $127 \mathrm{~A}$ and $127 \mathrm{~A} 232 \mathrm{Q}$ showed a very low toxicity and a high stability at the wide scope of $\mathrm{pH}$ and temperature.
They could be mixed used with types of drugs to reduce the usage of traditional antibiotics. Additionally, 127A and 127A232Q showed stronger protective effect against $S$. aureus than natural Lys and commercial Lys in mice. These results indicated the nonglycosylated lysostaphin is a potential effective drug for clinical treatment of $S$. aureus infection.

\section{DATA AVAILABILITY STATEMENT}

The original contributions presented in the study are included in the article/Supplementary Material, further inquiries can be directed to the corresponding author/s. 


\section{AUTHOR CONTRIBUTIONS}

RM and JW conceived and designed experiments. WS carried out all the experiments. DT, NY, and XM prepared partial materials in laboratory. WS, RM, and NY contributed in writing. JW contributed in funding acquisition. YH contributed to materials and reagents. All authors contributed to the article and approved the submitted version.

\section{FUNDING}

This study was supported by the National Natural Science Foundation of China (NSFC, Grant Nos. 31872393,

\section{REFERENCES}

Baba, T., and Schneewind, O. (1996). Target cell specificity of a bacteriocin molecule: a C-terminal signal directs lysostaphin to the cell wall of Staphylococcus aureus. EMBO J. 15, 4789-4797. doi: 10.1002/j.1460-2075.1996. tb00859.x

Basso, L. A., Schneider, C. Z., Santos, A. J. A. B. D., Santos, A. A. D., Campos, M. M., Soutoa, A. A., et al. (2010). An inorganic complex that inhibits Mycobacterium tuberculosis enoyl reductase as a prototype of a new class of chemotherapeutic agents to treat tuberculosis. J. Brazil Chem. Soc. 21, 1384-1389. doi: 10.1590/ S0103-50532010000700026

Bastos, M. D. C. D., Coelho, M. L. V., and Santos, O. C. D. S. (2015). Resistance to bacteriocins produced by Gram-positive bacteria. Microbiology 161, 683-700. doi: 10.1099/mic.0.082289-0

Bastos, M. D. C. D., Coutinho, B. G., and Coelho, M. L. V. (2010). Lysostaphin: a Staphylococcal bacteriolysin with potential clinical applications. Pharmaceuticals 3, 1139-1161. doi: 10.3390/ph3041139

Bause, E., and Hettkamp, H. (1979). Primary structural requirements for N glycosylation of peptides in rat liver. FEBS Lett. 108, 341-344. doi: 10.1016/ 0014-5793(79)80559-1

Becker, B., and Cooper, M. A. (2013). Aminoglycoside antibiotics in the 21st century. ACS Chem. Biol. 8, 105-115. doi: 10.1021/cb3005116

Cao, X., Zhang, Y., Mao, R., Teng, D., Wang, X., and Wang, J. (2015). Design and recombination expression of a novel plectasin-derived peptide MP1106 and its properties against Staphylococcus aureus. Appl. Microbiol. Biot. 99, 2649-2662. doi: 10.1007/s00253-014-6077-9

Ceotto Vigoder, H., Marques, S. L. S., Santos, I. N. S., Alves, M. D. B., Barrias, E. S., Potter, A., et al. (2016). Nisin and lysostaphin activity against preformed biofilm of Staphylococcus aureus involved in bovine mastitis. J. Appl. Microbiol. 121, 101-114. doi: 10.1111/jam.13136

Chai, C., Lee, K., and Oh, S. (2015). Synergistic inhibition of Clostridium difficile with nisin-lysozyme combination treatment. Anaerobe 34, 24-26. doi: 10.1016/ j.anaerobe.2015.04.003

Chandra, O. S., Imtong, C., Meetum, K., Sakdee, S., Katzenmeier, G., and Angsuthanasombat, C. (2018). Purification and characterization of the antibacterial peptidase lysostaphin from Staphylococcus simulans: adverse influence of $\mathrm{Zn}(2+)$ on bacteriolytic activity. Protein Expr. Purif. 151, 106-112. doi: 10.1016/j.pep.2018.06.013

Cheleuitte-Nieves, C. E., Diaz, L. L., Pardos, D. L. G. M., Gonzalez, A., Freiwald, W. A., de Lencastre, H. M., et al. (2020). Evaluation of topical lysostaphin as a novel treatment for instrumented rhesus macaques (Macaca mulatta) infected with methicillin-resistant Staphylococcus aureus. Comp. Med. 70, 335-347. doi: 10.30802/AALAS-CM-19-000102

Chen, C., Fan, H., Huang, Y., Peng, F., Fan, H., Yuan, S., et al. (2014). Recombinant lysostaphin protects mice from methicillin-resistant Staphylococcus aureus pneumonia. Biomed. Res. Int. 2014:602185. doi: 10.1155/2014/602185

Chen, P., and Harcum, S. W. (2006). Effects of elevated ammonium on glycosylation gene expression in CHO cells. Metab. Eng. 8, 123-132.
31772640, and 31702146); Key Project of Alternatives to Antibiotic for Feed Usages-the Agricultural Science and Technology Innovation Program (ASTIP, Grant Nos. CAASZDXT2018008); AMP Direction of National Innovation Program of Agricultural Science and Technology from Chinese Academy of Agricultural Sciences (Grant No. CAASASTIP-2013-FRI-02).

\section{SUPPLEMENTARY MATERIAL}

The Supplementary Material for this article can be found online at: https://www.frontiersin.org/articles/10.3389/fmicb. 2021.637662/full\#supplementary-material

Chu, X., Lin, Y., Sun, Z., Huan, L., and Zhong, J. (2010). Advances in the study of nisin resistance-a review. Wei Sheng Wu Xue Bao 50, 1129-1134.

Climo, M. W., Patron, R. L., Goldstein, B. P., and Archer, G. L. (1998). Lysostaphin treatment of experimental methicillin-resistant Staphylococcus aureus aortic valve endocarditis. Antimicrob. Agents Chem. 42, 1355-1360. doi: 10.1128/AAC. 42.6.1355

Duman, Z. E., Ünlü, A., Çakar, M. M., Ünal, H., and Binay, B. (2019). Enhanced production of recombinant Staphylococcus simulans lysostaphin using medium engineering. Prep. Biochem. Biotech. 49, 521-528. doi: 10.1080/10826068.2019. 1599393

Eichler, J. (2019). Protein glycosylation. Curr. Biol. 29, R229-R231. doi: 10.1016/j. cub.2019.01.003

Fan, W., Plaut, K., Bramley, A. J., Barlow, J. W., and Kerr, D. E. (2002). AdenoviralMediated transfer of a lysostaphin gene into the goat mammary gland. J. Dairy. Sci. 85, 1709-1716. doi: 10.3168/jds.s0022-0302(02)74244-6

Gleeson, A., Larkin, P., Walsh, C., and O'Sullivan, N. (2015). Methicillinresistant Staphylococcus aureus: prevalence, incidence, risk factors, and effects on survival of patients in a specialist palliative care unit: a prospective observational study. Palliat. Med. 30, 374-381. doi: 10.1177/0269216315595158

Goldberg, L. M., DeFranco, J. M., Watanakunakorn, C., and Hamburger, M. (1967). Studies in experimental Staphylococcal endocarditis in dogs. VI. Treatment with lysostaphin. Antimicrob. Agents Chem. 7, 45-53.

Gonzalez-Delgado, L. S., Walters-Morgan, H., Salamaga, B., Robertson, A. J., Hounslow, A. M., Jagielska, E., et al. (2020). Two-site recognition of Staphylococcus aureus peptidoglycan by lysostaphin SH3b. Nat. Chem Biol. 16, 24-30. doi: 10.1038/s41589-019-0393-4

Grishin, A. V., Lavrova, N. V., Lyashchuk, A. M., Strukova, N. V., Generalova, M. S., Ryazanova, A. V., et al. (2019). The influence of dimerization on the pharmacokinetics and activity of an antibacterial enzyme lysostaphin. Molecules 24:1879. doi: $10.3390 /$ molecules 24101879

Hamby, S. E., and Hirst, J. D. (2008). Prediction of glycosylation sites using random forests. BMC Bioinform. 9:500. doi: 10.1186/1471-2105-9-500

Han, C., Wang, Q., Sun, Y., Yang, R., Liu, M., Wang, S., et al. (2020). Improvement of the catalytic activity and thermostability of a hyperthermostable endoglucanase by optimizing $\mathrm{N}$-glycosylation sites. Biotechnol. Biofuels 13:30. doi: 10.1186/s13068-020-1668-4

Jahanshahi, A., Zeighami, H., and Haghi, F. (2018). Molecular characterization of methicillin and vancomycin resistant Staphylococcus aureus strains isolated from hospitalized patients. Microb. Drug Resist. 24, 1529-1536. doi: 10.1089/ mdr.2018.0069

Johnson, C. T., Wroe, J. A., Agarwal, R., Martin, K. E., Guldberg, R. E., Donlan, R. M., et al. (2018). Hydrogel delivery of lysostaphin eliminates orthopedic implant infection by Staphylococcus aureus and supports fracture healing. Proc. Natl. Acad. Sci. U.S.A. 115, E4960-E4969. doi: 10.1073/pnas.1801013115

Kaito, C., Saito, Y., Nagano, G., Ikuo, M., Omae, Y., Hanada, Y., et al. (2011). Transcription and translation products of the cytolysin gene psm-mec on the mobile genetic element SCCmec regulate Staphylococcus aureus virulence. PLoS Pathog. 7:e1001267. doi: 10.1371/journal.ppat.1001267 
Kiri, N., Archer, G., and Climo, M. W. (2002). Combinations of lysostaphin with beta-lactams are synergistic against oxacillin-resistant Staphylococcus epidermidis. Antimicrob. Agents Chem. 46, 2017-2020.

Kokai-Kun, J. F. (2012). Lysostaphin: A Silver Bullet for Staph. Wallingford: CABI.

Kokai-Kun, J. F., Chanturiya, T., and Mond, J. J. (2007). Lysostaphin as a treatment for systemic Staphylococcus aureus infection in a mouse model. J. Antimicrob. Chemother. 60, 1051-1059. doi: 10.1093/jac/dkm347

Kokai-Kun, J. F., Chanturiya, T., and Mond, J. J. (2009). Lysostaphin eradicates established Staphylococcus aureus biofilms in jugular vein catheterized mice. J. Antimicrob. Chemother. 64, 94-100. doi: 10.1093/jac/dkp145

Kokai-Kun, J. F., Walsh, S. M., Chanturiya, T., and Mond, J. J. (2003). Lysostaphin cream eradicates Staphylococcus aureus nasal colonization in a cotton rat model. Antimicrob. Agents Chem. 47, 1589-1597.

Laxminarayan, R., Duse, A., Wattal, C., Zaidi, A. K., Wertheim, H. F., Sumpradit, N., et al. (2013). Antibiotic resistance-the need for global solutions. Lancet Infect. Dis. 13, 1057-1098. doi: 10.1016/S1473-3099(13)70318-9

LeBel, M. (1988). Ciprofloxacin: chemistry, mechanism of action, resistance, antimicrobial spectrum, pharmacokinetics, clinical trials, and adverse reactions. Pharmacotherapy 8, 3-30. doi: 10.1002/j.1875-9114.1988.tb04058.x

Marshall, R. D. (1974). The nature and metabolism of the carbohydrate-peptide linkages of glycoproteins. Biochem. Soc. Symp. 40, 17-26.

Mierau, I., Leij, P., van Swam, I., Blommestein, B., Floris, E., Mond, J., et al. (2005). Industrial-scale production and purification of a heterologous protein in Lactococcus lactis using the nisin-controlled gene expression system NICE: the case of lysostaphin. Microb. Cell Fact. 4:15. doi: 10.1186/1475-2859-4-15

Montville, T. J., and Chen, Y. (1998). Mechanistic action of pediocin and nisin: recent progress and unresolved questions. Appl. Microbiol. Biotechnol. 50, 511-519. doi: $10.1007 / \mathrm{s} 002530051328$

Nilsson, I., and von Heijne, G. (2000). Glycosylation efficiency of Asn-Xaa-Thr sequons depends both on the distance from the $\mathrm{C}$ terminus and on the presence of a downstream transmembrane segment. J. Biol. Chem. 275, 17338-17343.

Park, J. T., and Strominger, J. L. (1957). Mode of action of penicillin. Science 125, 99-101. doi: 10.1126/science.125.3238.99

Qin, L., McCausland, J. W., Cheung, G. Y. C., and Otto, M. (2016). PSM-Mec-A virulence determinant that connects transcriptional regulation, virulence, and antibiotic resistance in staphylococci. Front. Microbiol. 7:1293.

Queck, S. Y., Khan, B. A., Wang, R., Bach, T. H., Kretschmer, D., Chen, L., et al. (2009). Mobile genetic element-encoded cytolysin connects virulence to methicillin resistance in MRSA. PLoS Pathog. 5:e1000533.

Recsei, P. A., Gruss, A. D., and Novick, R. P. (1987). Cloning, sequence, and expression of the lysostaphin gene from Staphylococcus simulans. Proc. Natl. Acad. Sci. U.S.A. 84, 1127-1131. doi: 10.1073/pnas.84.5.1127

Review on Antimicrobial Resistance (2017). Available online at: http://amr-review. org

Sabala, I., Jagielska, E., Bardelang, P. T., Czapinska, H., Dahms, S. O., Sharpe, J. A., et al. (2014). Crystal structure of the antimicrobial peptidase lysostaphin from Staphylococcus simulans. FEBS J. 281, 4112-4122. doi: 10.1111/febs.12929

Schindler, C. A., and Schuhardt, V. T. (1964). Lysostaphin: a new bacteriolytic agent for the Staphylococcus. Proc. Natl. Acad. Sci. U.S.A. 51, 414-421. doi: 10.1073/pnas.51.3.414

Sharma, R., Sharma, P. R., Choudhary, M. L., Pande, A., and Khatri, G. S. (2006). Cytoplasmic expression of mature glycylglycine endopeptidase lysostaphin with an amino terminal hexa-histidine in a soluble and catalytically active form in Escherichia coli. Protein Expres. Purif. 45, 206-215.

Stark, F. R., Thornsvard, C., Flannery, E. P., and Artenstein, M. S. (1974). Systemic lysostaphin in man-apparent antimicrobial activity in a neutropenic patient. N. Engl. J. Med. 291, 239-240.

Stavenhagen, K., Gahoual, R., Dominguez, V. E., Palmese, A., Ederveen, A., Cutillo, F., et al. (2019). Site-specific N- and O-glycosylation analysis of atacicept. MAbs 11, 1053-1063. doi: 10.1080/19420862.2019.1630218

Stürenburg, E. (2009). Rapid detection of methicillin-resistant Staphylococcus aureus directly from clinical samples: methods, effectiveness and cost considerations. Ger. Med. Sci. 7, 1-19. doi: 10.3205/000065

Tossavainen, H., Raulinaitis, V., Kauppinen, L., Pentikainen, U., Maaheimo, H., and Permi, P. (2018). Structural and functional insights into LysostaphinSubstrate interaction. Front. Mol. Biosci. 5:60. doi: 10.3389/fmolb.2018.00060

Vollmer, W., Blanot, D., and de Pedro, M. A. (2008). Peptidoglycan structure and architecture. FEMS Microbiol. Rev. 32, 149-167. von Eiff, C., Kokai-Kun, J. F., Becker, K., and Peters, G. (2003). In vitro activity of recombinant lysostaphin against Staphylococcus aureus isolates from anterior nares and blood. Antimicrob. Agents Chemother. 47, 3613-3615. doi: 10.1128/ aac.47.11.3613-3615.2003

Walsh, S., Shah, A., and Mond, J. (2003). Improved pharmacokinetics and reduced antibody reactivity of lysostaphin conjugated to polyethylene glycol. Antimicrob Agents Chemother. 47, 554-558. doi: 10.1128/aac.47.2.554-558.2003

Wang, X., Wang, X., Teng, D., Mao, R., Hao, Y., Yang, N., et al. (2018). Increased intracellular activity of MP1102 and NZ2114 against Staphylococcus aureus in vitro and in vivo. Sci. Rep. 8:4204. doi: 10.1038/s41598-018-22245-5

Wargo, K. A., and Edwards, J. D. (2014). Aminoglycoside-induced nephrotoxicity. J. Pharm. Pract. 27, 573-577. doi: 10.1177/0897190014546836

Waryah, C. B., Gogoi-Tiwari, J., Wells, K., Eto, K. Y., Masoumi, E., Costantino, P., et al. (2016). Diversity of virulence factors associated with west Australian Methicillin-Sensitive Staphylococcus aureus isolates of human origin. Biomed. Res. Int. 2016, 1-10. doi: 10.1155/2016/8651918

Wells, L., and Feizi, T. (2019). Editorial overview: carbohydrates: O-glycosylation. Curr. Opin. Struct. Biol. 56, 3-5. doi: 10.1016/j.sbi.2019.05.010

Yang, N., Liu, X., Teng, D., Li, Z., Wang, X., Mao, R., et al. (2017). Antibacterial and detoxifying activity of NZ17074 analogues with multi-layers of selective antimicrobial actions against Escherichia coli and Salmonella enteritidis. Sci. Rep. 7:3392. doi: 10.1038/s41598-017-03664-2

Yang, N., Teng, D., Mao, R., Hao, Y., Wang, X., Wang, Z., et al. (2019). A recombinant fungal defensin-like peptide-P2 combats multidrug-resistant Staphylococcus aureus and biofilms. Appl. Microbiol. Biotechnol. 103, 51935213. doi: 10.1007/s00253-019-09785-0

Yang, X. Y., Li, C. R., Lou, R. H., Wang, Y. M., Zhang, W. X., Chen, H. Z., et al. (2007). In vitro activity of recombinant lysostaphin against Staphylococcus aureus isolates from hospitals in Beijing, China. J. Med. Microbiol. 56, 71-76. doi: 10.1099/jmm.0.46788-0

Yang, Z., and Zhang, Z. (2018). Engineering strategies for enhanced production of protein and bio-products in Pichia pastoris: a review. Biotechnol. Adv. 36, 182-195. doi: 10.1016/j.biotechadv.2017.11.002

Zhang, J., Yang, Y., Teng, D., Tian, Z., Wang, S., and Wang, J. (2011). Expression of plectasin in Pichia pastoris and its characterization as a new antimicrobial peptide against Staphyloccocus and Streptococcus. Protein Expres. Purif. 78, 189-196. doi: 10.1016/j.pep.2011.04.014

Zhang, Q., Li, L., Lan, Q., Li, M., Wu, D., Chen, H., et al. (2019). Protein glycosylation: a promising way to modify the functional properties and extend the application in food system. Crit. Rev. Food Sci. Nutr. 59, 2506-2533. doi: 10.1080/10408398.2018.1507995

Zhang, Y., Teng, D., Wang, X., Mao, R., Cao, X., Hu, X., et al. (2015). In vitro and in vivo characterization of a new recombinant antimicrobial peptide, MP1102, against methicillin-resistant Staphylococcus aureus. Appl. Microbiol. Biot. 99, 6255-6266. doi: 10.1007/s00253-015-6394-7

Zhao, H., Blazanovic, K., Choi, Y., Bailey-Kellogg, C., and Griswold, K. E. (2014). Gene and protein sequence optimization for high-level production of fully active and aglycosylated lysostaphin in Pichia pastoris. Appl. Environ. Microb. 80, 2746-2753. doi: 10.1128/AEM.03914-13

Zheng, X., Wang, X., Teng, D., Mao, R., Hao, Y., Yang, N., et al. (2017). Mode of action of plectasin-derived peptides against gas gangrene-associated Clostridium perfringens type A. PLoS One 12:e185215. doi: 10.1371/journal. pone. 0185215

Zygmunt, W. A., and Tavormina, P. A. (1972). Lysostaphin: model for a specific enzymatic approach to infectious disease. Prog. Drug Res. 16, 309-333. doi: 10.1007/978-3-0348-7081-8_7

Conflict of Interest: The authors declare that the research was conducted in the absence of any commercial or financial relationships that could be construed as a potential conflict of interest.

Copyright $\odot 2021$ Shen, Yang, Teng, Hao, Ma, Mao and Wang. This is an openaccess article distributed under the terms of the Creative Commons Attribution License (CC BY). The use, distribution or reproduction in other forums is permitted, provided the original author(s) and the copyright owner(s) are credited and that the original publication in this journal is cited, in accordance with accepted academic practice. No use, distribution or reproduction is permitted which does not comply with these terms. 